\title{
IMPACT OF FEEDSTOCK DIVERSIFICATION ON THE COST-EFFECTIVENESS OF BIODIESEL
}

\author{
Ece Gülşen \\ Engineering Systems Division \\ Massachusetts Institute of Technology \\ 77 Massachusetts Ave \\ Cambridge, MA 02139 \\ Contact author: \\ Elsa Olivetti* \\ Engineering Systems Division \\ Massachusetts Institute of Technology \\ 77 Massachusetts Ave, E38 - 434 \\ Cambridge, MA 02139 \\ elsao@mit.edu \\ p: $617-253-0877$ \\ f: $617-258-7471$ \\ Fausto Freire \\ ADAI-LAETA, Department of Mechanical Engineering, University of Coimbra \\ Pólo II Campus, Rua Luís Reis Santos, \\ 3030-788 Coimbra, Portugal \\ Coimbra, Portugal \\ Luis Dias \\ INESC Coimbra, Faculdade de Economia. University of Coimbra, \\ Rua Antero de Quental, 3000-033 Coimbra, Portugal \\ Coimbra, Portugal \\ Randolph Kirchain \\ Engineering Systems Division \\ Massachusetts Institute of Technology \\ 77 Massachusetts Ave, E38 - 432 \\ Cambridge, MA 02139
}

This is a PDF file of an unedited manuscript that has been accepted for publication in Applied Energy:

The manuscript will undergo copyediting, typesetting, and review of the resulting proof before it is published in its final form. Please note that during the production process errors may be discovered which could affect the content, and all legal disclaimers that apply to the journal pertain. The final version will be available at: http://dx.doi.org/10.1016/j.apenergy.2014.03.063 


\section{ABSTRACT}

While biodiesel production and consumption for use in transportation has risen considerably over the last decade, its competiveness in the marketplace is largely due to regulatory and fiscal support from governmental bodies, exceeding \$25 billion in 2010 in the EU and US alone. The price of feedstocks represent $80-85 \%$ of the total biodiesel cost, and with over 350 different oil feedstocks available for blending, there is potential to optimize feedstock blends to reduce costs. This paper presents a chance-constrained optimization model that considers the technical constraints of conventional, first generation feedstocks, pricing trends, as well as the uncertainty and variation latent within these numbers. Further, the frequency with which a feedstock blend portfolio should be re-evaluated is considered through a case study. The model is then applied to a second case study for actual fuel constraint scenarios used in the EU and US. The results demonstrate the potential for substantial cost savings through targeted feedstock diversification, minimizing risks to producers from price fluctuations while still meeting technical fuel standards.

\section{INTRODUCTION}

Worldwide economic growth drives ever-increasing demand for energy across all economic sectors. For the transportation sector, this growth may translate into a rate of energy demand which nearly doubles by 2050 [1]. Meeting this demand securely and sustainably will require leveraging a range of solutions, including a shift to alternative and renewable fuels.

Despite controversies around its lifecycle greenhouse gas (GHG) emissions and potential contribution to increased food and feed prices [2-5], many believe that biodiesel will play an important role in the alternative fuel portfolio for transportation due to widespread policy goals. In fact, consumption of biodiesel has increased tremendously over recent years as a result of national energy policies worldwide [6]. In the US, domestic production and use of biodiesel rose from approximately 7.5 million liters in 2000 to 4 billion in 2011 [7-9]. Globally, demand is even greater. In the EU, biodiesel consumption has grown to over 10 billion liters [10], and the OECD-FAO projects global production to exceed 45 trillion liters by 2020 [11]. Unfortunately, this commitment to biodiesel comes at a cost. Currently, the production of biodiesel is more expensive than petrodiesel, and regulatory and fiscal governmental intervention is required to sustain the biodiesel market $[12,13]$. Steenblik [3] estimates that combined subsidies for biodiesel and bioethanol exceeded $\$ 25$ billion in 2010 in the US and EU alone [3]. While the short-term goal of these policies is to meet national renewable energy targets, the long-term expectation is that the biodiesel industry will mature into a cost-competitive alternative to petrodiesel.

Creating a self-sustaining biodiesel industry will require changes throughout the whole biodiesel supply chain: from feedstock cultivation to transport of feedstocks to biodiesel production through blending of these feedstocks [14]. Operational-level decision making at these production facilities, particularly the feedstock selection process for blending, appears to offer a significant opportunity to reduce production cost. For biodiesel produced by transesterification, feedstock costs represent between $80 \%-85 \%$ of the total production cost $[6,15,16]$. In addition, the individual feedstocks on which biodiesel depend exhibit high price volatility, threatening the long-term financial stability of 
any producer [17]. Skillful selection of a portfolio of raw materials at the producer level can provide a powerful financial advantage and, as this paper will show, if that portfolio is diversified it can stabilize costs, reducing financial risk.

Realizing the goal of nimble, diverse feedstock selection is challenging, however, for several reasons, including: 1) the number of available feedstocks (at least 350 identified to-date);[18] 2) the difficulty in mapping physical characteristics of the feedstocks to ultimate fuel performance; 3 ) the variation of feedstock properties (including prices) across time and location [18, 19], and 4) national policies that limit access to otherwise technically and/or economically attractive feedstocks.

Recognizing these complexities surrounding optimal feedstock selection at the producer level, this paper will a) describe a basic model by which producers can identify the best feedstocks for given market context; b) explore whether the optimal blend changes across market contexts, and c) characterize the potential economic value of adopting various approaches to risk mitigation through batch planning. The work contributes to the understanding of how feedstock diversification can help control costs while maintaining fuel quality, and under what contexts the benefit of diversification is most valuable. To accomplish these goals, a composition-based physical property prediction model has been developed for four key properties. Furthermore, a chanceconstrained (CC) optimization method, which explicitly considers the inherent uncertainty present in feedstock properties (or quality) using performance-based constraints, has been implemented for a few cases to find the minimum-cost blend portfolio for a given market context. Only conventional vegetable oils commonly used for biodiesel production have been studied in the scope of the work ${ }^{1}$. While case-based work focusing on four properties and select feedstocks is limited in its generalizability, this demonstration provides evidence that CC optimization in biodiesel blending models can identify production strategies that lower average cost and that hedge against price volatility for producers.

\subsection{Challenges in FeEdSTOCK SELECTION For Biodiesel}

Others have recognized that feedstock diversification may be an important issue for the biodiesel industry. For example, in an effort to control financial risks emerging from fluctuations in feedstock prices, some US producers have converted their facilities to multi feedstock use systems, especially after the price of soybean oil rose faster than diesel prices between 2007 and 2008 [7]. Furthermore, the US Department of Agriculture started to fund research on feedstock diversification. However, to date, there has been little quantitative research done on the potential cost implications of diversification strategies.

Meanwhile, identifying the optimal blend of raw materials to make a final product is not a new topic and has been explored for decades in many industries $[20,21]$ including the petroleum industry

\footnotetext{
${ }^{1}$ Feedstocks considered in this paper provide more than $80 \%$ of today's global biodiesel production and this trend is not likely to change soon. The authors acknowledge the applicability of the methods developed here on the $2^{\text {nd }}$ and $3^{\text {rd }}$ generation raw materials including biodiesel derived from waste-cooking oil. However further data is needed to properly apply the model on these raw materials.
} 
[22-24]. Methods have also been developed to explicitly consider uncertainty and integrate it into complex optimization problems [25]. To date, these models have limited treatment of biodiesel or employed performance-based specifications for biodiesel beyond empirical measurements of blends [26, 27]. A recent article explored blends of biodiesel-ethanol-diesel fuels to identify valuable additives as well as demonstrate profit improvements for firms using these blends through use of waste feedstocks [28]. Batch planning decisions in the biodiesel industry have primarily been based on fixed recipes derived from producer experience [18] and therefore previous work has extrapolated fuel prediction rules from this empirical work. The work presented here aims to derive these properties from building blocks of the feedstocks and then explicitly manage their uncertainty through chance constrained blending models.

Producers face two key challenges related to selecting appropriate feedstocks. These are 1) compliance with regionally-specific technical specifications and policy requirements, often not met by a single feedstock and thereby requiring blending of multiple feedstocks, and 2) uncertainty in feedstock properties coupled with price volatility. Helping operators make decisions about diversification requires an approach capable of dealing with these challenges through a tool that is capable of designing multi-feedstock blends and predicting the final fuel properties prior to blending. This capability can enable producers to modify the batch composition over time as prices fluctuate and thereby obtain cost-effective and technically compliant biodiesel capable of competing with petrodiesel.

Because feedstock cost is estimated to be a major part of the production cost $[15,16,26,29,30]$, cost reduction opportunities are strongly dependent on the feedstock prices. These prices not only differ from each other across feedstocks, but also fluctuate to a significant extent over time. Figure 1a shows some of these prices between January 2003 and June 2011, deflated by the FAO vegetable oil price index. When the relative prices among feedstocks shift based on the market conditions, a producer might need to modify the feedstock proportions used in the batch to remain profitable. As can be seen from Figure 1b, the correlations among deflated feedstock prices are either fairly weak and positive, or relatively strong and negative. Given that lack of strong positive correlations, the price behavior suggests that maintaining a diversified blend portfolio could be helpful to hedge against unexpected price changes in the market [31]. The ability to quickly adjust the blend portfolio in response to dynamics such as price fluctuations and availability in the market could bring substantial value to biodiesel producers. 


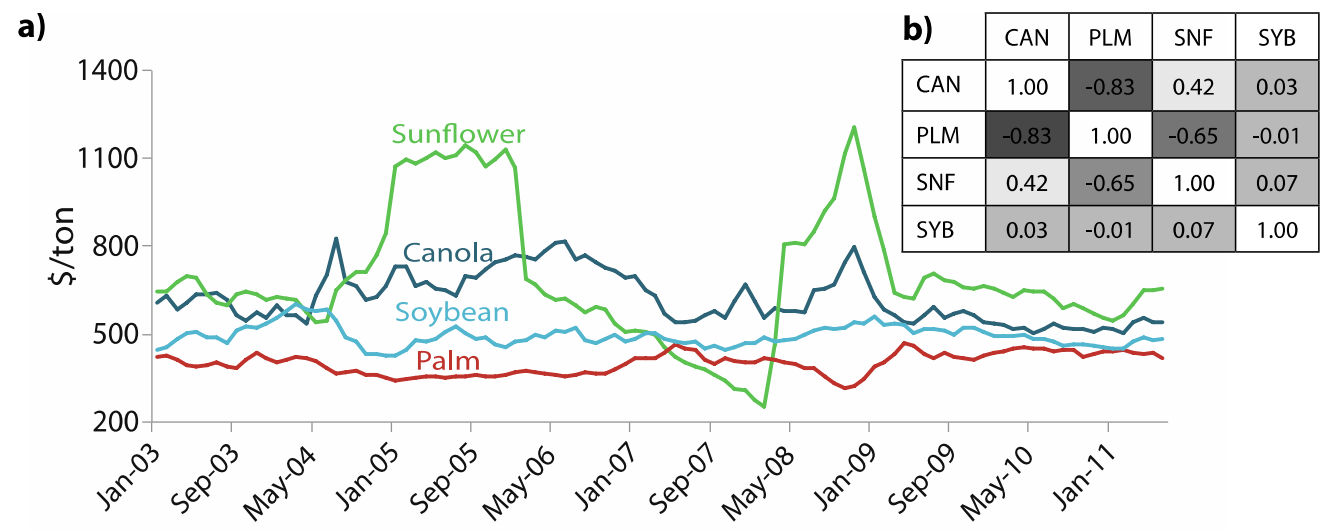

Figure 1 - a) Deflated vegetable oil prices between January 2003 and June 2011, deflated by the FAO vegetable oil index. Raw data is taken from [17] b) Correlation factors among deflated feedstock prices, January 2003 - June 2011.

\section{METHODS}

\subsection{Physical Property Prediction Model}

The physical characteristics of feedstocks typically used in a biodiesel batch differ from one another and these differences impact the characteristics of the final fuel. In most cases, a single feedstock is not able to meet all the technical specifications. These specifications also vary by region, for example, the EU has a higher oxidative stability standard compared to the US, and also enforces a maximum iodine value constraint that limits the use of soybean typically imported from the Americas.

Here we describe the development of the physical property prediction model to address the challenge of complying with four technical specifications. These four specifications were chosen among a larger list of specifications based on what industry indicated were most challenging to meet through a series of interviews with six biodiesel companies ${ }^{2}$.

Vegetable oils can be transformed into biodiesel via a transesterification reaction using methanol [32]. In general, each vegetable oil is composed of a range of six to eight different types of fatty

\footnotetext{
${ }^{2}$ These four specifications were identified as economically determinant parameters by the biodiesel producers - economic compromises in cost or operational efficiency were predominantly made to satisfy these four performance specifications. Nevertheless, economically determinant constraints could vary based on market context (specific consumer preferences, physical location, other feedstock types, etc.). When market context changes, other performance metrics may need to be developed and incorporated into the model.
} 
acids (FAs). ${ }^{3}$ These FAs are transformed into fatty acid methyl esters (FAMEs) at the end of transesterification. The majority biodiesel physical properties can be predicted by studying the characteristics of constituent FAMEs in the final fuel $[26,33]$. The following describes the four technical constraints used in the study and summarizes the property prediction models that were developed for this paper. In each case, property predication is based on FAME composition of the blend, and each property exhibits a range based on the compositional range of constituent feedstock FAs. More information can be found in Appendix A.

\subsubsection{IODINE VALUE (IV)}

Iodine value is the mass of iodine (in grams) consumed by 100 grams of FAME. It is a direct indication of the degree of unsaturation in the carbon chain, as a result of iodine's extreme reactivity with $\mathrm{sp}^{2}$ and $\mathrm{sp}$ hybridized carbons. A high degree of unsaturation is known to result in polymerization reactions in diesel engines under combustion conditions, and therefore is not desired [34]. Iodine value of a FAME can be calculated as in Eqn 1:

$$
I V_{\text {FAME }}=\frac{100 * M W_{I_{2}} * \# d b}{M W_{F A M E}}
$$

where $M W_{I_{2}}$ is the molecular weight of an iodine molecule, \#db is the number of double bonds in the FAME and $M W_{F A M E}$ is the molecular weight of the FAME molecule. Based on the IV of constituent FAMEs present, the property, $\mathrm{Q}_{\mathrm{IV}}$, of biodiesel can be calculated as in Eqn 2:

$$
Q_{I V_{B D}}=\sum_{i} a_{j} * I V_{F A M E_{j}}
$$

where $a_{j}$ is the volume proportion of $F A M E_{j}$ in biodiesel and $I V_{F A M E_{j}}$ is the IV of $F A M E_{j}$. The constraint for IV is a maximum constraint. $a_{j}$ can be calculated as in Eqn 3 based on the volume proportions of feedstocks in the blend:

$$
a_{j}=A_{i} * C_{j i}
$$

where $A_{i}$ is the volume proportion of feedstock $\mathrm{i}$, and $C_{j i}$ is the percent composition of $F A M E_{j}$ in feedstock i.

\subsubsection{CETANe Number (CN)}

$\mathrm{CN}$ of biodiesel is analogous to the octane rating in gasoline and is an indication of ignition quality. Similar to octane rating, it is a dimensionless descriptor. $\mathrm{CN}$ is generally not a concern for biodiesel when current feedstocks in the market are considered [35]. However, with the potential of increased feedstock diversification over the coming years, inclusion of new species might make this constraint binding. $\mathrm{CN}$ has been shown to map proportionally by volume, to the CNs of the constituent FAMEs. As such the property, $R_{C N}$, of biodiesel can be predicted using Eqn 4 [36]:

\footnotetext{
${ }^{3}$ Most common FAs found in vegetable oils are myristic acid, palmitic acid, stearic acid, oleic acid, linoleic acid and eruric acid.
} 


$$
R_{C N_{B D}}=\sum_{i} a_{j} * C N_{F A M E_{j}}
$$

The constraint for $\mathrm{CN}$ is a minimum constraint.

\subsubsection{COLD FILTER PLUGGing POINT (CFPP)}

Cold flow properties of biodiesel are of central concern, especially if the final fuel will be used in colder climates and the feedstock is highly saturated [35, 37]. In fact, cold flow performance is one of the main reasons to blend various types of vegetable oils. There are a few different standards that constrain the cold flow quality of biodiesel. These are cloud point (CP), freezing point (FP), low-temperature flow test (LTFT), pour point (PP) and cold filter plugging point (CFPP). This paper considers CFPP only, as a representative parameter for all the other cold flow parameters. Based on the proportionality between the CFPP and the percentage of saturated FAMEs, previous research shows that the property, $\mathrm{Q}_{\mathrm{CFP}}$, of biodiesel can be predicted as follows:

$$
Q_{C F P P_{B D}}=a *[\text { Sats }]_{F A M E}-b
$$

The constraint for CFPP is a maximum constraint. Where $a$ is the regression coefficient, [Sats] $]_{F A M E}$, is the percentage of saturated FAMEs in the fuel and $b$ is the intercept [38]. Regression parameters $\left(\mathrm{R}^{2}=0.86\right)$ used in this work are taken from [26].

The specific level of the CFPP constraint varies with the climate region and operation conditions.

\subsubsection{OXIDATIVE STABILITY (OS)}

Biodiesel might be transported over long distances and/or stored for significant durations. As such, fuel degradation due to oxidation is a major concern for the industry. The most common method to determine OS is the so-called Rancimat test. The Rancimat test determines the OS of biodiesel by measuring a metric called induction period, which is a direct indication of oxidizability of biodiesel. This work considers two major factors that influence oxidizability of biodiesel: 1) characteristics of unsaturation [39, 40], and 2) presence of natural antioxidants [41-43]. Based on an extensive survey of literature values concerning these considerations, a multiple regression model that predicts the induction period, and therefore the OS or the property Ros, of biodiesel is developed as in Eqn 6:

$$
R_{O S_{B D}}=\text { Induction Period }=a+b * B A P E+c * \gamma_{T}+d * T T
$$

where $B A P E$ is bis-allylic position equivalent ${ }^{4}, \gamma_{T}$ is the amount of $\gamma-$ tocopherol, TT is the amount of tocotrienol ${ }^{5}$ and $a, b, c, d$ are regression parameters. The constraint for OS is a minimum constraint. The regression model resulted in $\mathrm{R}^{2}=0.84$ with $\mathrm{p}$-value less than 0.001 for all the parameters.

As mentioned above, the physical characteristics of feedstocks investigated in the property prediction model exhibit uncertainty. This uncertainty arises mostly from the specific genetics of a

${ }^{4} B A P E$ is proportional to the amount of double or triple bonds in a particular FA.

5 The units of tocopherol and tocotrienol levels are dimensionless because literature reported values were converted into dummy variables prior to running the regression model. More details can be found in Appendix B. 
crop that determine the chemical composition, from environmental conditions during crop growth, and from handling and storage conditions along the supply chain $[19,43,44]$. In an attempt to capture the compositional uncertainty, several literature values of FA compositions for each vegetable oil have been collected as part of this study [35 and references therein]. Assuming a normal distribution around the mean values of each FA in each vegetable oil, composition profiles have been modeled. This normal distribution assumption presents some limitations to the extensibility of these results. Based on the equations described above and the range of FA compositions within a given vegetable oil type, 10,000 Monte Carlo simulations were run for biodiesel obtained from canola (or rapeseed), soybean, sunflower and palm oil, individually, and the prediction models were applied on every simulation to estimate the physical characteristics of the corresponding biodiesel. The $5^{\text {th }}$ and $95^{\text {th }}$ percentile values resulting from the models developed here were found to be within published literature values where ranges were reported for all four feedstocks with the exception of sunflower for CFPP and OS [35] and references therein. Details of these comparisons are provided in Appendix A. The prediction model results should be compared with a larger data set before use by the industry. These performance-property relationships along with their uncertainty were integrated into a batch planning algorithm as described in the next section.

\subsection{Chance-Constrained (CC) Optimization Model to Manage UnCERTainty}

To address the challenges of uncertainty and feedstock blending complexities, a chance-constrained (CC) optimization model was developed to inform decision making around blending on the producer level given feedstock price volatility and uncertainty in feedstock quality. Conventional approaches to incorporating uncertainty information into an optimal blending problem are known to result in overestimation of uncertainty, and therefore can lead to lower profitability [45-47]. Optimization under uncertainty has been extensively studied over recent years, and the methods developed constitute promising solutions to increase performance of decisions under uncertainty $[25,48]$. CC optimization, first formulated by Charnes and Cooper [49], is one such method that has been implemented in various optimization problems governed by compositional uncertainty. These models have investigated metal production of both steel and aluminum, coal blending, and animal feed [45, 50-54]. Owing to its capability to explicitly consider, propagate and control uncertainty in a mix of uncertain constituents, CC optimization offers a great potential for an optimal multi-feedstock biodiesel problem. In addition, one key characteristic of the CC method is the increased diversification of the solution portfolio compared to conventional optimization methods, which can benefit the producers by diversifying supply chain and reducing risk to price volatility.

The objective is to minimize the total feedstock cost, $\mathrm{P}(\mathrm{x})$, through optimal allocation of feedstock volumes, $A_{i}$ (Eqn 7). This optimization is subject to constraints around total normalized demand, D, as shown in Eqn 8. Supply constraints were formulated for completeness but not considered in the analysis. Finally for each feedstock property (IV, CN, CFPP, OS) the composition of the final fuel must not exceed the technical specifications (Eqn 9 and 10).

$$
\text { Min: } \quad P(x)=\sum_{i} P_{i} A_{i}
$$




$$
\begin{aligned}
\text { Subject to: } & \sum_{i} A_{i}=D \\
& \bar{Q}_{B}+\mathrm{X}(\alpha) \sigma_{Q_{B}} \leq Q_{\text {cons }} \\
& \bar{R}_{B}-\mathrm{X}(\alpha) \sigma_{R_{B}} \geq R_{\text {cons }}
\end{aligned}
$$

where;

$$
\begin{aligned}
& P_{i}: \text { feedstock } i \text {, price } \\
& A_{i}: \text { feedstock } i \text {, volume proportion } \\
& D: \text { normalized total demand } \\
& X(\alpha): \text { normal distribution test coefficient, one-tailed } \\
& \bar{Q}_{B}\left(\text { or } \bar{R}_{B}\right): \text { property } \mathrm{Q} \text { (or property } \mathrm{R} \text { ), mean value } \\
& Q_{\text {cons }},\left(\text { or } R_{\text {cons }}\right): \text { property } \mathrm{Q} \text { (or property R),constraint level } \\
& \sigma_{Q_{B}}, \sigma_{R_{B}}: \text { property } \mathrm{Q} \text { (or property R) standard deviation in blend }
\end{aligned}
$$

Standard deviations on the blend are derived based on the generalized equation as shown in Eqn 12:

$$
\sigma_{Q_{B}}, \sigma_{R_{B}}=\sqrt{\sum_{i} \sum_{j} \rho_{i j} \sigma_{i} \sigma_{j} A_{i} A_{j}}
$$

where $\rho_{i j}$ is the correlation coefficient between $i$ and $j$. By definition $\rho_{i j}=1$ when $i=j$. Because we assume no correlation between feedstocks, $\rho_{i j}=0$ when $i \neq j$. In other words, all feedstock scenarios considered in the model are regarded to be statistically independent from each other, whether or not they belong to the same crop species.

The volume proportions of each feedstock to be blended, namely $A_{i}$ constitute the decision variables of the optimization problem. Choosing a set of $A_{i}$ values determines the amount of each FAME, $a_{j}$, in the blend as was shown in Eqn 3. Because FAMEs are the building blocks that define all the physical parameters, we can derive IV, CN, OS and CFPP based on the FAME profile of the blend using the prediction model relations. The properties that are captured by Q above are IV and CFPP while R captures OS and CN. The derivation of these properties and the details of standard deviation estimations can be found in Appendix B. Finally, $\mathrm{X}(\alpha)$ is a user input that determines the maximum accepted non-compliance rate based on the value of $\alpha$. For all the physical properties considered in the model, $\alpha$ was chosen as $95 \%$, allowing a maximum $5 \%$ probability of noncompliance rate for each property. The integration of the property prediction models into the CC optimization enables the derivation of critical performance metrics from FAME compositional characteristics of the optimized blend. 


\section{RESULTS AND DISCUSSION}

Because the optimal blend portfolio is strongly dependent on the level of fuel constraints, two cases are designed to study the impact of different constraint levels. In the first case, constraint levels are selected such that no specific feedstock among canola, soybean, sunflower and palm is favored based on chemical properties. For example, OS was chosen as an average of the US and the EU limits, while the EU IV limit and the US CN limit were used to obtain a set of constraints that lower selection biases in the model for certain feedstocks. The goal of the first case study is to investigate the model behavior and the relevance of the CC optimization for biodiesel blending. In the second case, the constraint levels represent the specific technical standards applied in the US and the EU which favor domestic feedstocks. The second case study thereby investigates the application of this formulation to the specific regional contexts of the US and the EU. The monthly price data of each feedstock is obtained from [17] over a period from January 2003 to June 2011.

\subsection{CASE STUDY \#1:}

The first case study examines the feasibility of CC blending models in the biodiesel industry for a hypothetical set of fuel constraints. In the following, optimal blend results are reported for an arbitrarily chosen single period price followed by multiple period price data covering the months between January 2003 and June 2011.6 The fuel constraint levels are as follows: iodine value (IV): max 120; cetane number (CN): min 47; cold filter plugging point (CFPP): $\max -1^{\circ} \mathrm{C}$; and oxidation stability (OS): $\min 4.5$ hour.

In order to investigate the impact of feedstock diversification on the final fuel cost, eight different scenarios were run in which different sets of feedstocks were available for blending purposes. ${ }^{7}$ Figure 2 shows these eight availability scenarios on the $x$-axis and the resulting optimal blend feedstock costs on the y-axis for April 2007 deflated prices. As the figure suggests, moving left to right the total feedstock cost decreases with increasing diversification. The single feedstock biodiesel costs $\$ 567 /$ ton whereas the four-blended feedstock biodiesel costs $\$ 485 /$ ton, corresponding to a $14 \%$ savings with no investment.

${ }^{6}$ The latest available price data point at www.indexmundi.com at the time of the inquiry.

${ }^{7}$ Although there are a total of 15 different combinations for a 4-feedstock system, 7 of these combinations do not lead to technically feasible fuels and therefore are not considered. 


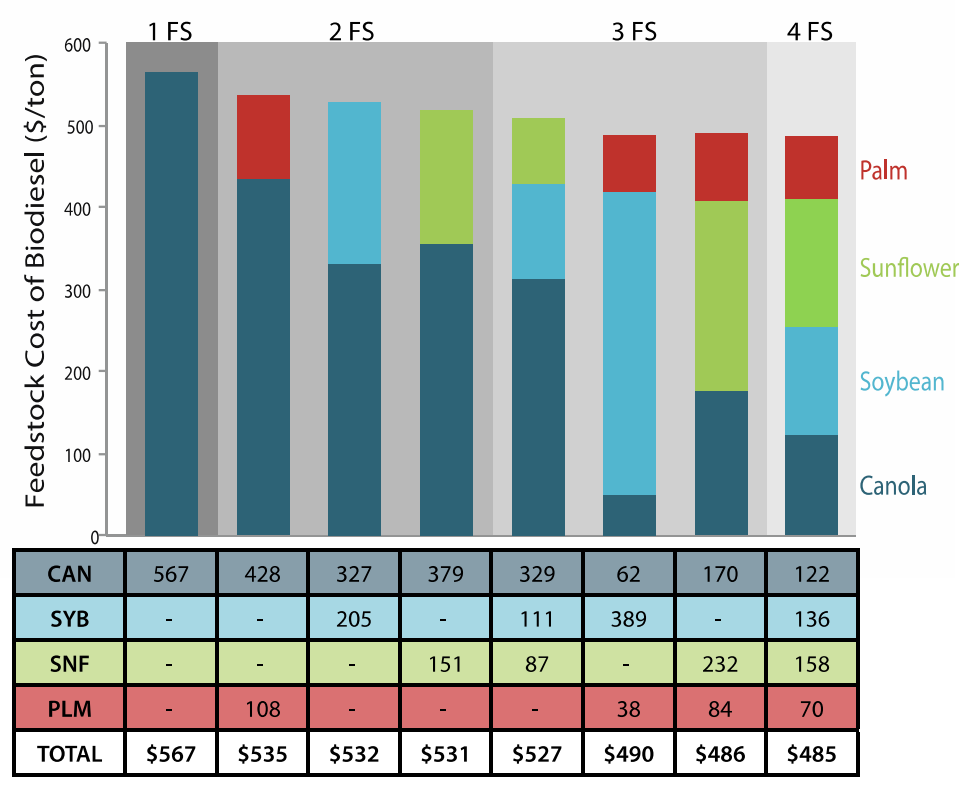

Figure 2 - Feedstock costs and optimal blend portfolios with respect to blend diversification.

In order to analyze the physical property distribution of each optimal blend and to assess how the blends perform with respect to the constraint levels, 10,000 Monte Carlo simulations were applied to each of the eight optimal blends. Simulation results show that diversification enables the proper control of the non-compliance rate of the final fuel as pre-determined by the model user. To give an example, the four-feedstock biodiesel complies with the $-1^{\circ} \mathrm{C}$ CFPP constraint with $95 \%$ probability having a mean value of $-1.3^{\circ} \mathrm{C}$ and a standard deviation of 0.19 ; however, the single feedstock biodiesel over-performs this constraint with a mean value of $-6^{\circ} \mathrm{C}$ and a standard deviation of 0.22 . In other words, $100 \%$ canola biodiesel possesses a very low CFPP level which the producers cannot transform into additional market value. Another conclusion drawn from the simulation distributions is the consistently lower standard deviations observed in more diversified blends. This observation is a manifestation of the risk-pooling capability of the model and implies that the level of uncertainty can be mitigated through feedstock diversification.

\subsubsection{Model APPLIED To MULTIPLE PERIOd PRICE DATA}

Feedstock prices are one of the major input parameters that impact the optimal portfolio calculated by the CC model. The previous analysis demonstrated the model behavior for a single month. Figure 3 shows the same eight scenarios of availability in the previous analysis produced by the optimization model; but here based on monthly prices observed between January 2003 and June 2011. The only feedstock that is feasible by itself is canola; however, the risk of price fluctuations, as well as the dependence on what could become an unreliable supply, make canola a less desirable choice. In fact, the optimal blend is often composed of at least three feedstocks, when those feedstocks are made available, given fluctuations in prices. Figure $3 c$ shows the variation in feedstock costs for the eight scenarios grouped by number of available feedstocks. The lowest and highest points for each blend set represent the $5^{\text {th }}$ and $95^{\text {th }}$ percentile and the black dots represent the medians. 
Overall, the trend demonstrated in Figure 3a reflects the trend found in Figure 2, indicating that as more feedstocks are available, the feedstock costs decrease. Additionally, the overall uncertainty tends to decrease. Consider the four-feedstock blend over this time period, CAN-SYB-SNF-PLM: it demonstrates a small degree of variation over time, but not the smallest among the blend sets. The exception to this trend in decreasing uncertainty is found in the CAN-SYB-PLM blend as compared to CAN-SYB-SNF-PLM. CAN-SYB-PLM has a tighter range, and hence smaller degree of cost uncertainty associated with it. However, the increased uncertainty in the four-feedstock blend emerges from the particular price behavior of sunflower and the resulting feedstock cost reduction opportunities manifested at certain points in time, particularly between January 2006 and February 2008 when sunflower prices were low as shown in Figure 1. More importantly, the upside risk of high prices is diminished in the four feedstock scenario.

The optimal blends over the study period for the CAN-SNF two-feedstock and the four-feedstock blends are highlighted in Figure 3b and 3c. The figures demonstrate how temporal fluctuations in price can lead to alterations in the final biodiesel composition given that the producers are flexible to blend multiple feedstocks based on prices. This flexibility has significant implications on the feedstock cost of biodiesel. For example, the CAN-SNF blend is primarily reliant on canola for the majority of the time, only incorporating sunflower during the sunflower price trough. This creates a consistently higher and more variable cost over time. On the other hand, the four-feedstock blend's inclusion of more feedstock options enables the producer to be flexible and vary the portfolio monthly according to the market prices to minimize the feedstock cost.
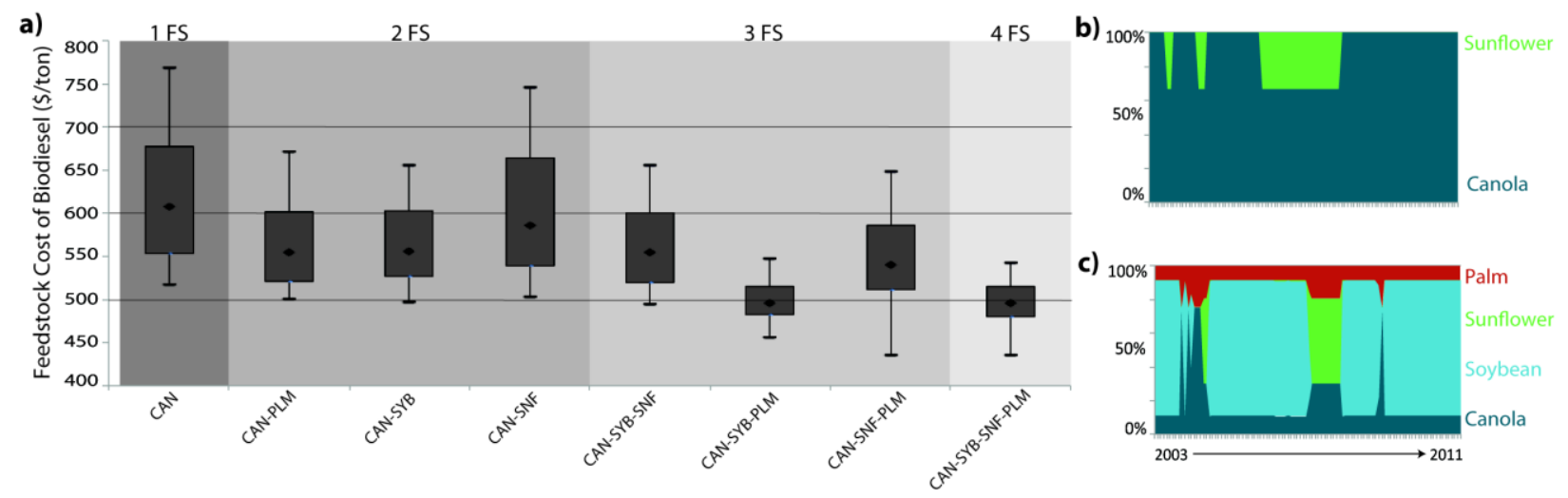

Figure 3- a) Range of feedstock costs for biodiesel blends optimized monthly between January 2003 and June 2011. The lowest and highest points for each blend set represent the $5^{\text {th }}$ and $95^{\text {th }}$ percentile and the black dots represent the medians. b) The optimal blend portfolios for the CAN-SNF two-feedstock biodiesel and c) the fourfeedstock biodiesel.

\subsubsection{DIFFERENT BLENDING STRATEGIES FOR COST CONTROL}

Lower feedstock costs can be achieved through optimized blending for each batch, monthly in this model, leading to cumulative savings over time. However, the operational challenges of optimizing the biodiesel batch over short time periods are not insignificant. For this reason, from the perspective of the producer, a trade-off exists between a strategy of achieving the lowest feedstock costs possible in each monthly period and the logistical benefits of maintaining a more consistent 
blend portfolio over a longer period of time to avoid switching. In the context of this model, an extreme case for the latter strategy would be using $100 \%$ canola oil for all batches, since it is the only feedstock that can individually satisfy technical requirements. However, as was shown in Figure 3, only using canola leads to higher costs and more significant risk to the producer; therefore, the producer should develop a strategy that leverages diversification while remaining logistically feasible ${ }^{8}$. Because of these operational challenges, we investigate the cost implications associated with three stationary blending strategies that can partially incorporate different advantages of the competing options mentioned above. The three potential blending strategies are:

\subsubsection{Max Diversified Strategy:}

Maintaining a diversified portfolio provides the producer protection from price fluctuations for individual crops. Therefore, choosing the most diversified portfolio possible and maintaining it over the entire time period could be a more simple approach over optimizing every batch in every period. The most significant advantage of this strategy is that it does not require any past, current, or future price knowledge. Determining the most diversified blend can be achieved by modifying the optimization formulation such that the objective is to maximize diversification. To find the most diversified blend possible within the technical constraints, the Herfindahl-Hirschmann Index (HHI) is used calculate the level of diversification [55]. Diversification in a system is maximized when the $\mathrm{HHI}$ is minimized. For modeling this strategy, the objective of the CC optimization was modified as in Eqn. 13 and all the constraints were kept the same.

$$
\operatorname{Min} H H I=\sum_{i} A_{i}^{2}
$$

\subsubsection{Stationary Strategy, Complete Price Informed:}

In the second scenario, a hypothetical situation is considered in which a producer sets a stationary blending rule throughout the period of interest and has complete information about the future prices ex ante. In this case, the optimal stationary portfolio would be the one that minimizes total costs integrated over time. ${ }^{9}$ While this strategy is not feasible to implement, it provides an idealized reference point to which the performance of other strategies can be compared. For modeling this strategy, the objective of the CC optimization was modified as in Eqn 14 and all the constraints were kept the same.

$$
\text { Min: } \sum_{i, t} P_{i, t} A_{i, t}
$$

where $P_{i, t}$ is deflated price of feedstock $i$ in time period $t$, and $A_{i, t}$ is the volume proportion of feedstock $i$ in the blend in time period $t$.

\subsubsection{Semi-stationary, Historic Price Informed:}

\footnotetext{
${ }^{8}$ A future study could explore the optimal frequency of recipe change for batches provided that there is access to detailed operational cost information.

${ }^{9}$ Note that we use deflated prices to find the optimal portfolio. Otherwise, because the nominal prices are larger in magnitude in the more recent years due to inflation, the optimal blend portfolio would be biased by the latest prices observed in the market.
} 
Recognizing the real-world impossibility of the Stationary Strategy, the Semi-stationary blending rule uses the blend portfolio which minimizes the previous year's total feedstock costs.

Optimization is performed on an annual basis using this strategy. Because consecutive years' prices are expected to be similar, adjusting the blend annually using this method could provide a limited degree of cost certainty to the producer.

Figure 4 shows the cumulative feedstock costs for an average annual production volume of 100,000 tons for the three Blending Strategies alongside the optimized blend portfolios discussed above (shown as green bars). The y-axis represents the total cost of the feedstock over the period of 20032011 for each strategy.

Based on these results, the four-feedstock blend optimized monthly has the greatest cost advantage with approximately $\$ 8.8$ million less than the next best performer over period 2003-2011. However, the stationary blends show some potential for cost savings. The Stationary Strategy exhibits the lowest cost of the potential blending approaches, at $\$ 647.9$ million, representing the lower bound of the stationary blends. Diversified strategy, with its high but fixed level of diversification, has the highest cost, \$727 million, with a price similar to that of the three-feedstock blends. Finally, the Semi-stationary falls between Diversified and Stationary at $\$ 679$ million, but is still higher than the two cheapest monthly-optimized portfolios. Comparison of Diversified and Semi-stationary with the monthly optimization scenarios indicates that a well-designed stationary blending rule can approximately achieve the cost performance equivalent to that of two or threefeedstock blend sets over time, however a four-feedstock blend optimized monthly will outperform others over time.

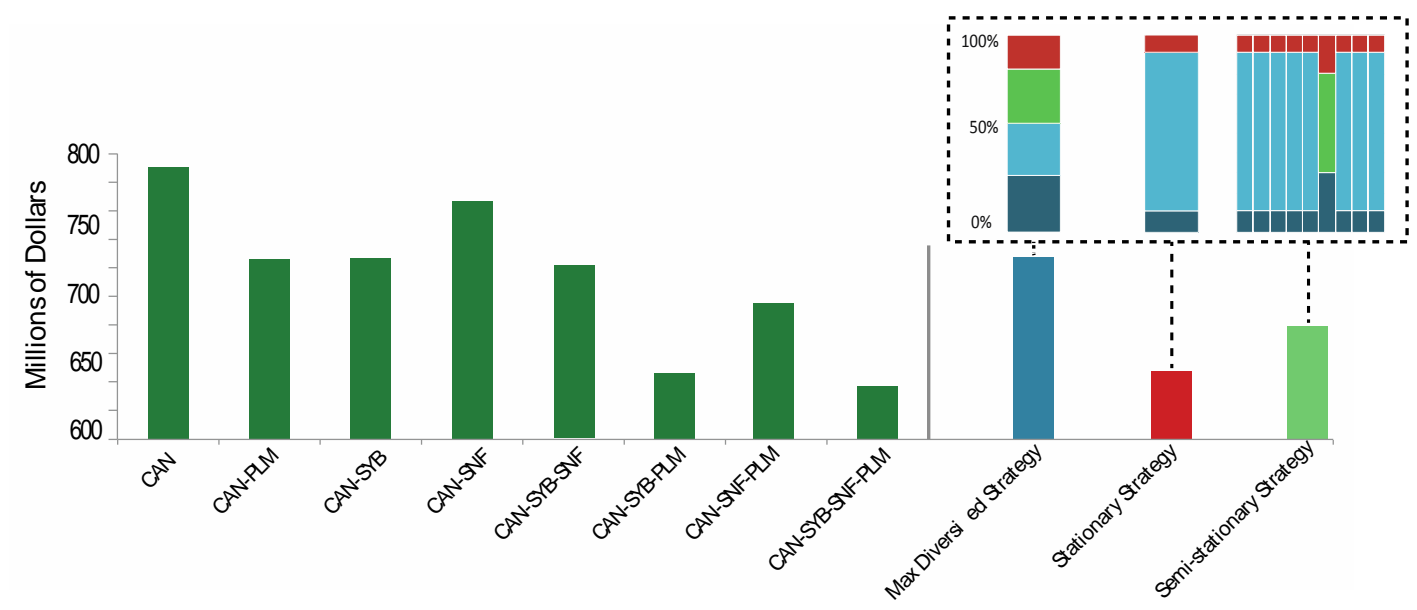

Figure 4 - Cumulative feedstock costs for optimal blends. Blend components are limited to the feedstocks on the $\mathrm{x}$ axis. Figures are in nominal dollars.

While this model only addresses four feedstocks for biodiesel, there is a wide range of other feedstocks not considered that have the potential to increase the diversity of portfolios and further spread the risk associated with lower quality materials across multiple feedstocks. For example, a new oil seed, camelina has gained approval by the US EPA in 2012 [56], and other oil seeds have 
become prominent in the world market, thereby providing a wider feedstock selection. The inclusion of additional biodiesel types depends on the technical constraints of new feedstock.

Assuming emerging crop types are compatible with technical specifications, the addition of new feedstocks will likely serve to reduce the cumulative portfolio costs and minimize variability over time. It is also possible that lower quality fuels, such as waste cooking oils, can be more significantly incorporated into more diverse biodiesel blends, further decreasing costs [57].

\subsection{CASE STUDY \#2: US AND EU}

The first case study examined the diversification behavior of the CC optimization under a hypothetical set of constraints. We now investigate the performance of the model under actual fuel constraint levels used in the EU and US markets. As mentioned above, EN 14214 enforced in the EU and ASTM D6751 enforced in the US require compliance with a set of fuel specifications. These specifications tend to favor domestic feedstocks within each of these regions. IV has no requirement within the US, while in the EU the maximum IV is 120 . For CN, the minimum values within the US and EU are 47 and 51, respectively. OS for the US and EU is a minimum of 3 and 6 hours, respectively. ${ }^{10} \mathrm{CFPP}$ is typically determined regionally based on climate and customer requirements. For this model the maximum limit was chosen as $-1^{\circ} \mathrm{C}$.

Figure 5 shows the feedstock cost based on monthly prices between January 2003 and June 2011 for three different scenarios each for the EU (left hand side of the figure) and the US contexts (right hand side). The lowest and highest points for each blend set represent the $5^{\text {th }}$ and $95^{\text {th }}$ percentile and the black dots represent the average. Note that the disparity in the different regional contexts suggests that regulators have latitude in specifications to achieve policy goals.

The first scenario for the EU, using only canola as a feedstock, is as shown in Figure 4, and repeated here for comparison purposes. The two-feedstock case for the EU includes canola, as before, and palm. Palm was chosen as the second available feedstock because sunflower is a minor feedstock worldwide and soybean oil is not typically used within the EU. When soybean and sunflower are made available in the EU, the overall feedstock cost decreases because the producer can take advantage of price fluctuations and adjust the blend rule accordingly in each period. More importantly, the overall cost uncertainty decreases, demonstrating robustness to price fluctuation.

The US biodiesel industry is dominated by soybean oil because of the high production of soybean crop in the US; in 2011, US-produced soybeans represented 56\% of world oilseed production[9]. Therefore, soybean is included in the blend for the three US scenarios shown on the right in Figure 5. Similarly, the US Environmental Protection Agency (EPA) recently declared that the oil obtained from palm, which is mostly cultivated in Indonesia and Malaysia, does not comply with its GHG emission reduction criteria and therefore cannot be used towards the production of renewable biodiesel [58] . Contrary to the EU scenario described above, palm is excluded from the twofeedstock blend due to the above mentioned ruling by the EPA on palm [58]. It must be noted that $100 \%$ soybean biodiesel is actually not an optimal solution for the CC model, because its

\footnotetext{
108 hour pending for the EU.
} 
compliance rate with respect to the 3 -hour OS limit is less than $70 \%$. Indeed, as Figure 5 shows, this is why soybean scenario costs less than the scenario in which two feedstocks are made available. As Figure 5 demonstrates, when four feedstocks are made available to the producer, the producer pays lower feedstock costs compared to using $100 \%$ soybean oil, in addition to obtaining a feasible blend in each period with respect to the technical constraints specified. The minimum cost that can be achieved within the given time period is $\$ 384 /$ ton when four feedstocks are available as opposed to $\$ 445 /$ ton when the supply is restricted to soybean. The average prices observed are $\$ 486 /$ ton and $\$ 494 /$ ton, respectively.

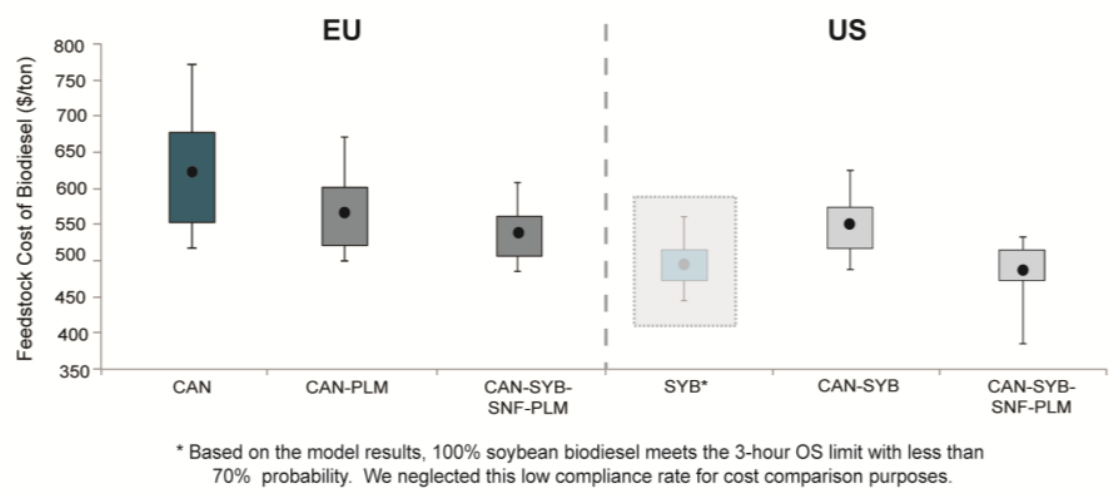

Figure 5 - Box plots of feedstock costs of biodiesel blends optimized monthly between January 2003 and June 2011 for the EU (left) and US context (right). The lowest and highest points for each blend set represent the $5^{\text {th }}$ and $95^{\text {th }}$ percentile and the black dots represent the average.

\section{CONCLUSIONS}

Through this model development and case investigation the benefits of a CC optimization to blend conventional biodiesel feedstocks have been shown. This study confirmed that feedstock diversification can help control costs while maintaining fuel quality by spreading the risk of price volatility across multiple feedstocks. Producers should attempt to select a diverse set of raw materials to reduce their exposure to price volatility risk by hedging against price variations over time. With the availability of new feedstock options and continued price volatility, the complexity of the decision space emphasizes the value of analytical decision making tools in the biodiesel industry that could minimize costs while ensuring fuel quality [59, 60]. Emerging GHG emissions regulations on biodiesel feedstocks, which the authors wish to address in future work, will further differentiate within crops and therefore provide further variety in the type of feedstocks available. Future work should also include investigation of other properties beyond the four examined here, explore implementation of non-normal characteristics for the feedstock property distributions as well as including more than the four feedstocks explored in this paper. Particularly, studying $2^{\text {nd }}$ and $3^{\text {rd }}$ generation biodiesel feedstocks with the methods developed here could contribute to faster adoption of more sustainable biodiesel production in the industry due to the potential to reduce costs [61-63]. Including lower quality feedstocks such as waste cooking oil would be of particular interest for the CC formulation. With increasing feedstock options emerging in the market, there is a 
significant opportunity for cost-effective biodiesel that can be obtained by increasing the feedstock selection capability for producers via analytical decision making tools.

\section{ACKNOWLEDGEMENTS}

The authors would like to acknowledge support from the Portuguese Science and Technology Foundation (FCT), in the context of the following 2 projects: MIT/SET/0014/2009 (Biofuel capturing uncertainty in biofuels for transportation: resolving environmental performance and enabling improved use), funded in the scope of the MIT-Portugal program; and PTDC/SENTRA/117251/2010 (Extended "well-to-wheels" assessment of biodiesel for heavy transport vehicles). The authors would also like to acknowledge funding from the National Science Foundation Award \# 1133422, Environmental Sustainability Program (ENG-CBET) that made this work possible. The authors extend their utmost thanks to Suzanne Greene for her important graphic and organizational contributions.

\section{REFERENCES}

[1] IEA/OECD. Transport, Energy and CO2: Moving Toward Sustainability. International Energy Agency 2009.

[2] NPR. World Bank Chief: Biofuels Boosting Food Prices. NPR2008.

[3] Steenblik R. Government support for ethanol and biodiesel in selected OECD countries: A synthesis of reports addressing subsidies for biofuels in Australia, Canada, the European Union, Switzerland and the United States. Report prepared for the Global Subsidies Initiative, International Institute for Sustainable Development, Geneva September http://www globalsubsidies org/files/assets/oecdbiofuels pdf (accessed June 1, 2009). 2007.

[4] Malça J, Freire F. Life-cycle studies of biodiesel in Europe: A review addressing the variability of results and modeling issues. Renewable and sustainable energy reviews. 2011;15:338-51.

[5] Chen ST, Kuo HI, Chen CC. Modeling the relationship between the oil price and global food prices. Appl Energy. 2010;87:2517-25.

[6] Demirbas A. Political, economic and environmental impacts of biofuels: A review. Appl Energy. 2009;86:S108-S17.

[7] Carter E, Ardjosoediro I. The U.S. Biodiesel Market, 2000 to 2010: Riding the Rollercoaster. In: FAS/USDA, editor.: Office of Global Analysis; 2011.

[8] Sims B. Keeping Pace. Biodiesel Magazine. 2012.

[9] American Soybean Association. SoyStats: A Reference Guide to Important Soybean Facts \& Figures. www.soystats.com 2012 .

[10] Flach B, Lieberz S, Bendz K, Dahlbacka B, Achilles D. EU-27 Biofuels Annual-EU Annual Biofuel Report. USDA Foreign Agricultural Service. The Hague, the Netherlands; 2011.

[11] OECD/FAO. BIOFUEL - OECD-FAO Agricultural Outlook 2011-2020. OECD; 2010.

[12] Strategic Energy Technologies Information System, Biofuels for the Transport Sector. In: JRC, editor.: EU; 2011.

[13] Ji Q, Fan Y. How does oil price volatility affect non-energy commodity markets? Appl Energy. 2012;89:273-80. 
[14] Tan RR, Aviso KB, Barilea IU, Culaba AB, Cruz JB. A fuzzy multi-regional input-output optimization model for biomass production and trade under resource and footprint constraints. Appl Energy.

2012;90:154-60.

[15] Retka-Schill S. Walking a tightrope. Biodiesel Mag. 2008;5:64-70.

[16] Group CC. Soybeans and Biodiesel: Key Price Relationships. 2009.

[17] Index Mundi. http://www.indexmundi.com/.

[18] Basha S, Gopal K, Jebaraj S. A review on biodiesel production, combustion, emissions and performance. Renewable and sustainable energy reviews. 2009;13:1628-34.

[19] Dolde D, Vlahakis C, Hazebroek J. Tocopherols in breeding lines and effects of planting location, fatty acid composition, and temperature during development. Journal of the American Oil Chemists' Society. 1999;76:349-55.

[20] Hutton RF, Allison J. A linear programming model for development of feed formulas under milloperating conditions. Journal of Farm Economics. 1957;39:94-111.

[21] Metzger R, Schwarzbek R. A linear programming application to cupola charging. J Ind Eng. 1961;12:87-93.

[22] Snee R. Developing blending models for gasoline and other mixtures. Technometrics. 1981;23:119-

30.

[23] Li J, Karimi I, Srinivasan R. Recipe determination and scheduling of gasoline blending operations. AIChE Journal. 2010;56:441-65.

[24] Singh A, Forbes JF, Vermeer PJ, Woo SS. Model-based real-time optimization of automotive gasoline blending operations. Journal of Process Control. 2000;10:43-58.

[25] Bertsimas D, Sim M. The price of robustness. Operations Research. 2004:35-53.

[26] Moser BR. Influence of Blending Canola, Palm, Soybean, and Sunflower Oil Methyl Esters on Fuel Properties of Biodieselt. Energy \& Fuels. 2008;22:4301-6.

[27] Park JY, Kim DK, Lee JP, Park SC, Kim YJ, Lee JS. Blending effects of biodiesels on oxidation stability and low temperature flow properties. Bioresource Technology. 2008;99:1196-203.

[28] Lin J, Gaustad G, Trabold TA. Profit and policy implications of producing biodiesel-ethanol-diesel fuel blends to specification. Appl Energy. 2013;104:936-44.

[29] A Technology Performance and Regulatory Review. Jefferson City, MO: American Biofuels Association \& Information Resources, INC.; 1994. p. 118.

[30] Haas M, McAloon A, Yee W, Foglia T. A process model to estimate biodiesel production costs. Bioresource Technology. 2006;97:671-8.

[31] Markowitz H. Portfolio Selection. The Journal of Finance. 1952;7:77-91.

[32] Balat M, Balat H. Progress in biodiesel processing. Appl Energy. 2010;87:1815-35.

[33] Harrington K. Chemical and Physical properties of vegetable oil esters and their effect on diesel fuel performance. Biomass. 1986;9:1-17.

[34] Knothe G. Structure indices in FA chemistry. How relevant is the iodine value? Journal of the American Oil Chemists' Society. 2002;79:847-54.

[35] Knothe G, Van Gerpen J, Krahl J, Press C. The Biodiesel Handbook. 2nd ed: AOCS press Champaign, IL; 2010.

[36] Clements LD. Blending Kules for Formulating Biodiesel Fuel. 1996.

[37] Imahara H, Minami E, Saka S. Thermodynamic study on cloud point of biodiesel with its fatty acid composition. Fuel. 2006;85:1666-70.

[38] Knothe G, Matheaus AC, Ryan TW. Cetane numbers of branched and straight-chain fatty esters determined in an ignition quality tester. Fuel. 2003;82:971-5.

[39] Kamal-Eldin A. Effect of fatty acids and tocopherols on the oxidative stability of vegetable oils. European Journal of Lipid Science and Technology. 2006;108:1051-61. 
[40] Frankel EN. Lipid oxidation: Oily Press Dundee, Scotland; 1998.

[41] Fröhlich A, Schober S. The influence of tocopherols on the oxidation stability of methyl esters. Journal of the American Oil Chemists' Society. 2007;84:579-85.

[42] Liang YC, May CY, Foon CS, Ngan MA, Hock CC, Basiron Y. The effect of natural and synthetic antioxidants on the oxidative stability of palm diesel. Fuel. 2006;85:867-70.

[43] Mittelbach M, Schober S. The influence of antioxidants on the oxidation stability of biodiesel. Journal of the American Oil Chemists' Society. 2003;80:817-23.

[44] Jain S, Sharma M. Stability of biodiesel and its blends: a review. Renewable and sustainable energy reviews. 2010;14:667-78.

[45] Gaustad G, Li P, Kirchain R. Modeling methods for managing raw material compositional uncertainty in alloy production. Resources, Conservation and Recycling. 2007;52:180-207.

[46] Olivetti EA, Gaustad GG, Field FR, Kirchain RE. Increasing Secondary and Renewable Material Use: A Chance Constrained Modeling Approach To Manage Feedstock Quality Variation. Environmental Science \& Technology. 2011.

[47] Wendt M, Li P, Wozny G. Nonlinear Chance-Constrained Process Optimization under Uncertainty. Industrial \& Engineering Chemistry Research. 2002;41:3621-9.

[48] Sahinidis NV. Optimization under uncertainty: state-of-the-art and opportunities. Computers \& Chemical Engineering. 2004;28:971-83.

[49] Charnes A, Cooper WW. Chance-constrained programming. Management Science. 1959:73-9.

[50] Kumral M. Application of chance-constrained programming based on multi-objective simulated annealing to solve a mineral blending problem. Engineering Optimization. 2003;35:661-73.

[51] Shih J-S, Frey HC. Coal blending optimization under uncertainty. European Journal of Operational Research. 1995;83:452-65.

[52] Rong A, Lahdelma R. Fuzzy chance constrained linear programming model for optimizing the scrap charge in steel production. European Journal of Operational Research. 2008;186:953-64.

[53] Cetinkaya M, Karaosmano lu F. Optimization of base-catalyzed transesterification reaction of used cooking oil. Energy Fuels. 2004;18:1888-95.

[54] Van de Panne C, Popp W. Minimum-cost cattle feed under probabilistic protein constraints. Management Science. 1963:405-30.

[55] Rhoades S. The Herfindahl-Hirschman Index. Federal Reserve Bulletin. 1993;79.

[56] Regulation of Fuels and Fuel Additives: Identification of Additional Qualifying Renewable Fuel Pathways Under the Renewable Fuel Standard Program. Federal Register2012.

[57] Talebian-Kiakalaieh A, Amin NAS, Mazaheri H. A review on novel processes of biodiesel production from waste cooking oil. Appl Energy. 2013;104:683-710.

[58] Notice of Data Availability Concerning Renewable Fuels Produced From Palm Oil Under the RFS Program. Federal Register2012. p. 4300-18.

[59] Leung DYC, Wu X, Leung MKH. A review on biodiesel production using catalyzed transesterification. Applied Energy. 2010;87:1083-95.

[60] Yan YJ, Li X, Wang GL, Gui XH, Li GL, Su F, et al. Biotechnological preparation of biodiesel and its high-valued derivatives: A review. Applied Energy. 2014;113:1614-31.

[61] Azadi P, Brownbridge G, Mosbach S, Smallbone A, Bhave A, Inderwildi O, et al. The carbon footprint and non-renewable energy demand of algae-derived biodiesel. Applied Energy. 2014;113:1632-44.

[62] Chisti Y, Yan JY. Energy from algae: Current status and future trends Algal biofuels - A status report. Applied Energy. 2011;88:3277-9.

[63] Wang R, Song BA, Zhou WW, Zhang YP, Hu DY, Bhadury PS, et al. A facile and feasible method to evaluate and control the quality of Jatropha curcus L. seed oil for biodiesel feedstock: Gas chromatographic fingerprint. Applied Energy. 2011;88:2064-70. 


\section{APPEndix A: Chemical Compositions of Biodiesel FeEdSTOCKS}

The constituent components of biodiesel feedstocks are mainly triglycerides-esters of glycerol and fatty acids (FAs) that undergo transesterification. During transesterification, triglycerides react with methanol ${ }^{11}$, and methyl esters of FAs (FAMEs) are obtained as the final fuel. Glycerol is a byproduct of the reaction. Assuming that there is no contamination during transesterification, and the byproducts and catalysts are completely removed from the system, physical characteristics of biodiesel are directly related to the inherent FAs within vegetable oils. A number of structural manifestations of these FAs have direct or indirect impact on biodiesel characteristics. These manifestations include, but not limited to;

- Length of the carbon chain,

- Presence, number and location of double bonds,

- $\quad$ Cis vs. trans isomerism, etc.

As an example, the presence of double bonds leads to higher oxidation rates, or longer carbon chains tend to possess higher melting points. FA compositions of most common feedstocks have been analyzed in the literature by chromatographic measurements. Table A1 provides the details of reported compositions [1]. Although a rough differentiation can be made across vegetable oil types based on compositional information, significantly wide compositional ranges are reported within vegetable oil types.

Table A1 - FA composition profiles in percentages [1]. Numbers in brackets represent minimum and maximum percentage of the FA in the feedstock.

\section{FA Composition (wt \%)}

\begin{tabular}{ccccccccc}
\hline & $\mathbf{1 2 : 0}$ & $\mathbf{1 4 : 0}$ & $\mathbf{1 6 : 0}$ & $\mathbf{1 8 : 0}$ & $\mathbf{1 8 : 1}$ & $\mathbf{1 8 : 2}$ & $\mathbf{1 8 : 3}$ & $\mathbf{2 2 : 1}$ \\
\hline Canola & & {$[0.1,0.2]$} & {$[3.3,6]$} & {$[1.1,2.5]$} & {$[52,67]$} & {$[16,25]$} & {$[6.5,14]$} & {$[0,0.2]$} \\
Palm & {$[0,0.4]$} & {$[0.5,2]$} & {$[40,47.5]$} & {$[3.5,6]$} & {$[36,44]$} & {$[6.5,12]$} & {$[0,0.5]$} & \\
Sunflower & {$[0,0.1]$} & {$[0,0.2]$} & {$[5.6,7.6]$} & {$[2.7,6.5]$} & {$[14,40]$} & {$[48,74]$} & {$[0,0.2]$} & {$[0,0.2]$} \\
Soybean & & {$[0,0.2]$} & {$[8,13]$} & {$[2.5,5.5]$} & {$[18,26]$} & {$[50,57]$} & {$[5.5,9.5]$} & \\
\hline
\end{tabular}

We use the compositional information given in Table $\mathrm{A} 1$ as a building block to derive physical characteristics of individual feedstocks. Moreover, because blends of these individual feedstocks are essentially mixtures of the tabulated FAs, it could be possible to model any blend property based on the proportions of the FAs in the mix. We assign the average of the reported compositions in Table $\mathrm{A} 1$ as the mean value of the distribution, and estimate a standard deviation for a normal distribution assuming that the reported ranges cover 6 standard deviations of the whole distribution ${ }^{12}$. Figure A1 shows the information given in Table A1 graphically with the addition of the error bars representing compositional standard deviations.

\footnotetext{
11 Other alcohol derivatives can be used, however methanol is commonly preferred due to cost and processing considerations.
}

${ }^{12}$ Approximately 99\% of all the possible values of a normally distributed random variable fall within the 6 standard deviations range. 


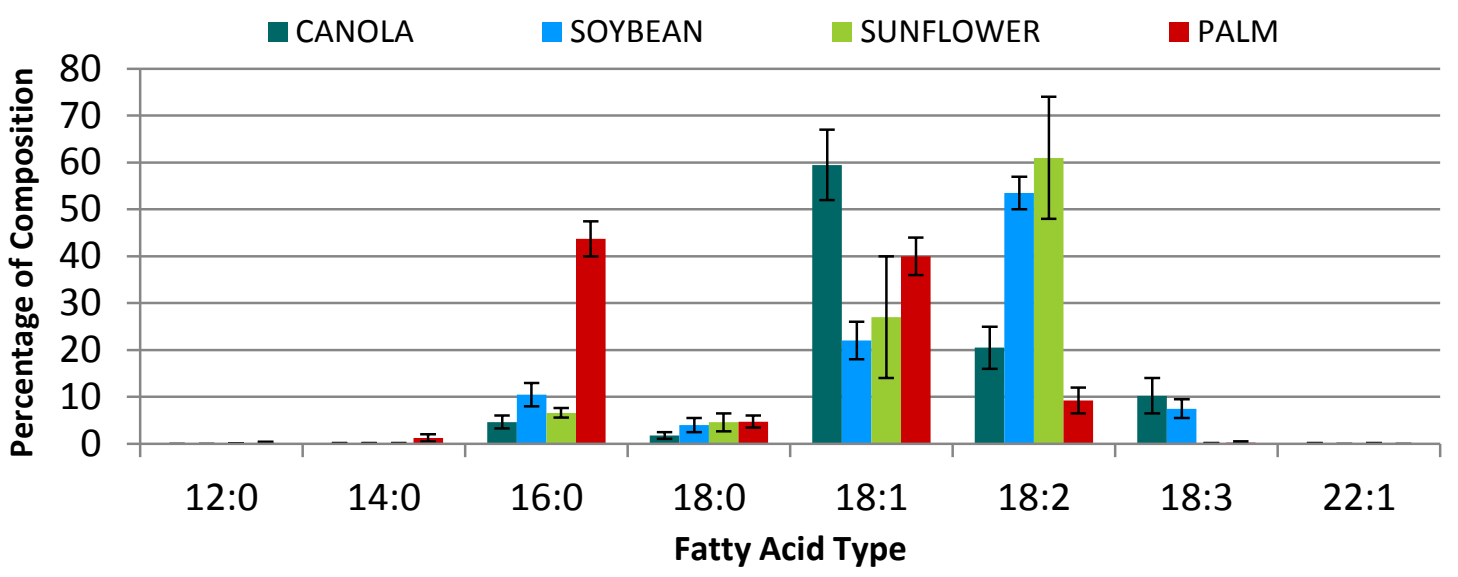

Figure A1- Compositions of FAs in each feedstock. In the x-axis, the first number represents the number of carbon atoms and the second number represents the number of double bonds.

\section{Verification of FeEdstock Physical Property Prediction}

IODINE VALUE (IV)

IV is enforced as a technical constraint under EN 14214, with maximum allowed value being 120. This constraint particularly limits the amount of soybean and sunflower oil used in biodiesel, due to their higher linoleic and linolenic content. We modeled IVs of canola, palm, soybean and sunflower based on the compositional information shown in Figure A1. Then, we ran Monte Carlo simulations to reflect the potential IV range for each feedstock.

Table A2 compares the literature reported IV ranges with the ranges predicted by the model. The model and the reported values are in good agreement with each other.

Table A2 - Comparison of $5^{\text {th }}$ and $95^{\text {th }}$ percentile IV values predicted by the model and the ranges reported in the literature.

\begin{tabular}{rcc}
\hline & Model IV Prediction & Reported IV in Literature \\
\hline Canola & {$[101,116]$} & {$[94,120]$} \\
Palm & {$[45,52]$} & {$[50,55]$} \\
Sunflower & {$[110,136]$} & {$[110,143]$} \\
Soybean & {$[120,129]$} & {$[120,143]$} \\
\hline
\end{tabular}

Model results indicate that IV does not become a binding constraint most of the time, because the optimal blend is never primarily composed of soybean and/or sunflower. Both canola and palm, having lower IVs, can offset their impact in the final fuel.

\section{CETANE NUMBER (CN)}

$\mathrm{CN}$ is determined based on the ignition performance of the fuel relative to a straight chain hydrocarbon, hexadecane $\left(\mathrm{C}_{16} \mathrm{H}_{34}\right)$ and a highly branched hydrocarbon, 2,2,4,4,6,8,8-

heptamethylnoane $\left(\mathrm{C}_{16} \mathrm{H}_{34}\right)$. Both substances are considered to be the primary reference fuels and assigned CNs of 100 and 15 respectively. Minimum CN requirement is 51 under EN 14214, and 47 under ASTM D6751. An Ignition Quality Tester (IQT) or a cetane engine can be used to determine the $\mathrm{CN}$ of biodiesel. It is not trivial to predict the $\mathrm{CN}$ of a hydrocarbon blend. Both gasoline and diesel industry have historically relied on empirical studies and experience to assess octane rating or $\mathrm{CN}$ of blends $[2-7,8]$. 
Table A3 lists measured CN of various FAMEs that used in the model. Note that it is possible to find slightly different $\mathrm{CN}$ data concerning these FAMEs in the literature. We believe the differences in measurements emerge from several factors pertaining to the complications in measurement procedures.

Table A3 - CNs of various neat FAMEs.

\begin{tabular}{ccccccccc}
\hline & $\mathbf{1 2 : 0}$ & $\mathbf{1 4 : 0}$ & $\mathbf{1 6 : 0}$ & $\mathbf{1 8 : 0}$ & $\mathbf{1 8 : 1}$ & $\mathbf{1 8 : 2}$ & $\mathbf{1 8 : 3}$ & $\mathbf{2 2 : 1}$ \\
\hline $\mathrm{CN}$ & $61.4^{\mathrm{a}}$ & $66.2^{\mathrm{a}}$ & $74.5^{\mathrm{a}}$ & $86.9^{\mathrm{a}}$ & $59.3^{\mathrm{b}}$ & $38.2^{\mathrm{b}}$ & $22.7^{\mathrm{a}}$ & $74.2^{\mathrm{a},{ }^{*}}$ \\
\hline
\end{tabular}

As listed in Table A4, agreement between the modeled CNs and literature reported values is promising.

Table A4 - Comparison of $5^{\text {th }}$ and $95^{\text {th }}$ percentile model estimates and literature reported values of CN.

\begin{tabular}{ccc}
\hline FAME & Model CN Estimate & CN Reported [1] \\
\hline Canola & {$[48.6,54.1]$} & $47.9^{\mathrm{a}}, 56^{\mathrm{a}}$ \\
Palm & {$[62.8,67.2]$} & $62^{\mathrm{b}}$ \\
\hline Sunflower & {$[43.3,53.6]$} & $54^{\mathrm{a}}, 58^{\mathrm{a}}$ \\
\hline Soybean & {$[44.6,48.5]$} & $49.6^{\mathrm{a}}, 55.9^{\mathrm{a}}$ \\
\hline
\end{tabular}

a Taken from [1]; ${ }^{\mathrm{b}}$ Taken from [10].

\section{COLD FILTER PLUGGING POINT (CFPP)}

A thermodynamic modeling study found that the amount of saturation was the main determinant for $\mathrm{CP}$ of biodiesel regardless of composition of unsaturated esters [11]. Likewise, a recent study [10] concluded that CFPP is linearly related to the proportion of saturated fats in the compound, and this relation can be expressed as in Eqn $\mathrm{A} 1\left(\mathrm{R}^{2}=0.86\right)$ :

$$
\text { CFPP }=0.438 *[\text { Sats }]-8.93
$$

where [Sats] is the percentage of saturated compounds in the fuel.

We modeled CFPP values of the most common biodiesel feedstocks based on their FA composition, and performed Monte Carlo analysis to explore potential ranges. Table A5 compares our model results with the literature reported values, which are in close agreement with each other.

Table A5 - Comparison of $5^{\text {th }}$ and $95^{\text {th }}$ percentile model predictions and the literature reported values for CFPP.

\begin{tabular}{ccc}
\hline FAME & Model CFPP Estimate, o- & Literature CFPP Reported ${ }^{*}$, $\mathbf{C}$ \\
\hline Canola & {$[-6.4,-5.7]$} & {$[-7,-4]$} \\
Palm & {$[11.9,13.8]$} & {$[10,16]$} \\
Sunflower & {$[-4.5,-3.5]$} & {$[-4,-1]$} \\
Soybean & {$[-3.2,-1.9]$} & {$[-5,-2]$} \\
\hline${ }^{*}$ Data taken from $[1]$. &
\end{tabular}

Note that the model does not consider the presence of any minor constituents present naturally or artificially in the feedstock. For example, it is known that vegetable oils naturally contain steryl glucosides (StG) which turn into free StG (FStG) upon transesterification. FStG are known to possess very high melting points $(\sim 240 \stackrel{\circ}{\circ})$ that could have a considerable effect on cold flow properties [1]. Similarly, trace amounts of monoacylglycerol (MAG), diacylglycerol (DAG) and triacylglycerol (TAG) that may remain after partial transesterification are known to negatively 
impact the low temperature operability performance. Consideration of these other factors requires more specific data along with more detailed models.

OXIDATIVE STABILITY (OS)

We have considered two major factors that influence oxidizability of biodiesel: 1) characteristics of unsaturation, and 2) presence of natural antioxidants.

\section{1) Characteristics of Unsaturation}

The presence of unsaturation in FAs facilitates higher rates of oxidation, and FAs have varying susceptibility for oxidation depending on the relative location of unsaturation in the carbon chain and the nature of unsaturation, such as hybridization of carbon atoms $[12,13]$. Due to the delocalization of the double bonds adjacent to the allylic and bis-allylic carbon atoms, $\mathrm{C}$ - $\mathrm{H}$ bonds in the allylic and bis-allylic positions are weaker and easier to break. As a result, these atoms are highly prone to oxidation, with bis-allylic position possessing even a higher reactivation rate. Knothe defines two indices, allylic position equivalent (APE) and bis-allylic position equivalent (BAPE), in order to represent these positions in a carbon chain; and shows that compounds having very similar IVs might have distinctively different APE and BAPE indices [14]. Table A6 lists the calculated APE and BAPE indices for some neat FAMEs.

Table A6- Calculated APE and BAPE indices of FAMEs commonly found in biodiesel.

\begin{tabular}{ccc}
\hline FAME & APE & BAPE \\
\hline Methyl Oleate 18:1 & 200 & 0 \\
Methyl Linoleate 18:2 & 200 & 100 \\
Methyl Linoleneate 18:3 & 200 & 200 \\
Methyl Erucate 22:1 & 200 & 0 \\
\hline
\end{tabular}

2) Presence of Natural Antioxidants in the Vegetable Oil

It is well known that most unrefined vegetable oils contain natural antioxidants such as tocopherols or tocotrienols, yet these naturally-occurring constituents are usually removed or deactivated by refining, distillation or transesterification processes [15-17]. Table A7 tabulates the distribution of the two most common antioxidants in the major feedstocks.

Table A7 - Tocopherol and tocotrienol values found in the literature (ppm).

\begin{tabular}{|c|c|c|c|c|c|c|c|c|}
\hline & $\alpha-\mathbf{T}^{*}$ & $\beta-T$ & $\gamma-\mathrm{T}$ & $\delta-T$ & $\alpha-\mathbf{T T}^{* *}$ & $\beta$-TT & $\gamma$-TT & $\delta$-TT \\
\hline \multirow{4}{*}{ Canola } & $179 a$ & & $409 a$ & & \multirow{4}{*}{-} & \multirow{4}{*}{-} & \multirow{4}{*}{-} & \multirow{4}{*}{ - } \\
\hline & $202^{b}$ & $\mathrm{~b}$ & $490^{b}$ & $9 \mathrm{~b}$ & & & & \\
\hline & $314^{c}$ & $18^{c}$ & $420^{c}$ & $14^{c}$ & & & & \\
\hline & $180^{d}$ & & $340^{d}$ & & & & & \\
\hline \multirow{3}{*}{ Palm } & $89 b$ & $7^{c}$ & $18^{\mathrm{b}}$ & \multirow{3}{*}{$6^{c}$} & \multirow{3}{*}{$\begin{array}{c}12^{\mathrm{b}} \\
52^{\mathrm{d}}\end{array}$} & \multirow{3}{*}{$\overline{4}^{\mathrm{d}}$} & \multirow{3}{*}{$323^{b}$} & \multirow{3}{*}{$72^{b}$} \\
\hline & $122^{c}$ & & $39 c$ & & & & & \\
\hline & $377 d$ & $1^{\mathrm{d}}$ & $4^{d}$ & & & & & \\
\hline \multirow{4}{*}{ Soybean } & $93^{a}$ & $11^{\mathrm{a}}$ & $1046^{a}$ & $374^{a}$ & \multirow{4}{*}{-} & \multirow{4}{*}{-} & \multirow{4}{*}{ - } & \multirow{4}{*}{ - } \\
\hline & $100^{\mathrm{b}}$ & $8^{b}$ & $1021^{b}$ & $421^{b}$ & & & & \\
\hline & $62^{c}$ & $11^{c}$ & $537 c$ & $147^{c}$ & & & & \\
\hline & $116^{d}$ & $17^{\mathrm{d}}$ & $578^{d}$ & $263^{d}$ & & & & \\
\hline Sunflower & $981^{\mathrm{a}}$ & $27 \mathrm{~b}$ & $11^{b}$ & $1^{b}$ & - & - & - & - \\
\hline
\end{tabular}




\begin{tabular}{lllcc}
\hline $670^{\mathrm{b}}$ & $21^{\mathrm{c}}$ & $118^{\mathrm{c}}$ & $19^{\mathrm{c}}$ \\
$497^{\mathrm{c}}$ & $23^{\mathrm{d}}$ & $4^{\mathrm{d}}$ & \\
$671^{\mathrm{d}}$ & & & \\
\hline${ }^{*}$ Tocopherol: & ${ }^{* *}$ Tocotrienol & & \\
\hline
\end{tabular}

"Tocopherol; $\quad{ }^{* *}$ Tocotrienol

${ }^{a}$ Averages of reported values in [18]; b Taken from [19]; c Taken from [10]; d Taken from [13].

As can be seen in Table A7, although each feedstock has more or less of a characteristic distribution of antioxidants, absolute tocopherol or tocotrienol levels could be quite different across different samples of the same feedstock type. It should be reiterated that on top of all the complexities listed, the possible variation in the storage time of the samples might introduce another degree of bias to the collected data as antioxidants tend to degrade over time. Even more, the vessel that transports the vegetable oil might have an impact on the resulting oxidative stability of the biodiesel, because it is shown that the presence of copper, iron and nickel reduces OS as a result of catalytic effect [20]. Despite all these factors, controlled experiments have shown that natural antioxidants stabilize methyl esters by reducing the rate of peroxide formation considerably [15]. Therefore, we attempted to capture the impact of naturally occurring antioxidants in our model. With few data points regarding the tocopherol and tocotrienol levels, we decided to represent the antioxidant levels with dummy variables; 0 representing absence, and 1 representing presence of the antioxidant in consideration. Furthermore, we considered only $\gamma$-tocopherol and tocotrienols, because $\alpha$-tocopherols are found to be the least effective stabilizers [15,21], and $\beta$ - and $\delta$ tocopherols are found in very small amounts in all the seed oils. Table A8 summarizes the dummy variable selection for the model. Note that sunflower oil possesses no major natural antioxidant in our model.

Table A8- Selected dummy variables for $\gamma$ tocopherol and tocotrienol levels in feedstocks.

\begin{tabular}{rcc}
\hline & $\boldsymbol{\gamma}$-T & TT $(\alpha+\beta+\gamma+\delta)$ \\
\hline Canola & 1 & 0 \\
Palm & 0 & 1 \\
Soybean & 1 & 0 \\
Sunflower & 0 & 0
\end{tabular}

Lastly, we assumed a linear blending model for the dummy variables when feedstocks are mixed with each other.

\section{Multiple Regression Analysis on Unsaturation and Natural Antioxidants}

Given the strong dependence of OS on unsaturation and natural antioxidant levels, we performed a multiple regression analysis of induction period on these two factors. Table A9 tabulates the induction period data used. Some measurements are based on blends of feedstocks and the blend ratios are indicated in the table. Total number of samples is 69.

Table A9 - Reported induction periods of several feedstocks and their blends. Rancimat method was used in all experiments. Total number of samples is 69.

\begin{tabular}{cccccc}
\hline FEEDSTOCKS & $\begin{array}{c}\text { Blend } \\
\text { Ratio }\end{array}$ & $\begin{array}{c}\text { Induction } \\
\text { Period }(\mathrm{h})\end{array}$ & FEEDSTOCKS & $\begin{array}{c}\text { Blend } \\
\text { Ratio }\end{array}$ & $\begin{array}{c}\text { Induction } \\
\text { Period (h) }\end{array}$ \\
\hline CAN & - & $6.4^{\mathrm{a}}$ & CAN/SNF & $1: 1$ & $6.5^{\mathrm{a}}$ \\
& - & $6.9^{\mathrm{b}}$ & & $1: 3$ & $6.8^{\mathrm{a}}$ \\
& - & $6.9^{\mathrm{g}}$ & & $3: 1$ & $6.2^{\mathrm{a}}$ \\
& - & $9.1^{\mathrm{h}}$ & $\mathbf{P L M} / \mathbf{S Y B}$ & $1: 1$ & $6.2^{\mathrm{a}}$ \\
& - & $7.8^{\mathrm{i}}$ & & $1: 3$ & $5.5^{\mathrm{a}}$ \\
\hline
\end{tabular}




\begin{tabular}{|c|c|c|c|c|c|}
\hline & - & $11.0^{\mathrm{b}}$ & & $1: 9$ & $5.2^{\mathrm{a}}$ \\
\hline & - & $14.2^{\mathrm{c}}$ & & $1: 4$ & $5.4^{\mathrm{a}} ; 4.2^{\mathrm{b}}$ \\
\hline & - & $11.1^{\mathrm{d}}$ & & $3: 7$ & $5.6^{a}$ \\
\hline & - & $15.4^{\mathrm{i}}$ & & $2: 3$ & $5.9^{a}$ \\
\hline & - & $13.4^{\mathrm{f}}$ & & $3: 2$ & $6.9^{a}$ \\
\hline \multirow[t]{6}{*}{ SYB } & - & $5.0^{\mathrm{a}}$ & & $7: 3$ & $7.4^{\mathrm{a}}$ \\
\hline & - & $3.9^{b}$ & & $4: 1$ & $8.2^{\mathrm{a}} ; 7.4^{\mathrm{b}}$ \\
\hline & - & $3.9^{c}$ & & $9: 1$ & $9.2^{\mathrm{a}}$ \\
\hline & - & $3.5^{d}$ & & $2: 3$ & $5.0^{\mathrm{b}}$ \\
\hline & - & $6.6^{e}$ & & $3: 2$ & $6.2^{\mathrm{b}}$ \\
\hline & - & $3.8^{f}$ & PLM/SNF & $1: 1$ & $8.1^{\mathrm{a}}$ \\
\hline \multirow[t]{4}{*}{$\mathrm{SNF}$} & - & $6.2^{\mathrm{a},{ }^{*}}$ & & $1: 3$ & $7.1^{\mathrm{a}}$ \\
\hline & - & $1.8^{\mathrm{c}}$ & & $3: 1$ & $9.2^{\mathrm{a}}$ \\
\hline & - & $3.4^{\mathrm{h}}$ & SYB/SNF & $1: 1$ & $5.8^{\mathrm{a}}$ \\
\hline & - & $1.7^{\mathrm{f}}$ & & $1: 03$ & $6.4^{\mathrm{a}}$ \\
\hline \multirow[t]{6}{*}{ CAN/PLM } & $1: 1$ & $7.6^{\mathrm{a}}$ & & $3: 1$ & $5.4^{\mathrm{a}}$ \\
\hline & $1: 3$ & $9.6^{\mathrm{a}}$ & CAN/PLM/SYB & 1:1:1 & $5.4^{\mathrm{a}}$ \\
\hline & $3: 1$ & $6.5^{\mathrm{a}}$ & & $1: 1: 3$ & $5.0^{\mathrm{b}}$ \\
\hline & $4: 1$ & $7.8^{b}$ & & $2: 1: 2$ & $5.7 \mathrm{~b}$ \\
\hline & $3: 2$ & $9.3^{\mathrm{b}}$ & & $3: 1: 1$ & $6.6^{\mathrm{b}}$ \\
\hline & $2: 3$ & $10.6^{b}$ & & $1: 2: 2$ & $6.3^{b}$ \\
\hline \multirow[t]{7}{*}{ CAN/SYB } & $1: 1$ & $5.3^{\mathrm{a}}$ & & $2: 2: 1$ & $7.7^{b}$ \\
\hline & $1: 3$ & $5.1^{\mathrm{a}}$ & & $1: 3: 1$ & $8.0^{\mathrm{b}}$ \\
\hline & $3: 1$ & $5.9^{\mathrm{a}}$ & CAN/PLM/SNF & $1: 1: 1$ & $7.8^{\mathrm{a}}$ \\
\hline & $4: 1$ & $4.2^{\mathrm{b}}$ & CAN/SYB/SNF & $1: 1: 1$ & $5.0^{\mathrm{a}}$ \\
\hline & $2: 3$ & $4.7 \mathrm{~b}$ & SYB/SNF/PLM & 1:1:1 & $6.7^{a}$ \\
\hline & $3: 2$ & $5.2^{\mathrm{b}}$ & CAN/PLM/SYB/SNF & $1: 1: 1: 1$ & $5.7^{\mathrm{a}}$ \\
\hline & $4: 1$ & $5.9^{b}$ & & & \\
\hline
\end{tabular}

a [10]; b [22]; c [17]; d [23]; e [24]; f [25]; g [26]; h [21]; i [15]

Table A10 details the antioxidant levels, chemical compositions and the resultant APE and BAPE indices corresponding to the samples listed in Table A9: 
Table A10- Antioxidant levels (dummy variables), chemical composition (\%) and resulting APE and BAPE indices of several feedstocks and their blends. The data is taken from the same resources as in Table 9. Total number of samples is 69.

\begin{tabular}{|c|c|c|c|c|c|c|c|c|c|c|c|c|c|c|c|c|c|}
\hline FEEDSTOCK & $\begin{array}{l}\text { Blend } \\
\text { Ratio }\end{array}$ & $V-T$ & $\pi$ & $12: 0$ & $14: 0$ & $16: 0$ & $16: 1$ & $18: 0$ & $18: 1$ & $18: 2$ & $18: 3$ & $20: 0$ & $20: 1$ & 22:0 & $22: 1$ & APE & BAPE \\
\hline Canola & - & 1 & - & - & - & 4.6 & 0.2 & 2.1 & 64.3 & 20.2 & 7.6 & 0.7 & - & 0.3 & - & 184.6 & 35.4 \\
\hline Canola & - & 1 & - & - & 0.1 & 4.4 & - & 1.7 & 62.4 & 19.7 & 9.5 & 0.6 & 1.3 & - & - & 185.76 & 38.67 \\
\hline Canola & - & 1 & - & - & - & 4.8 & - & 1.4 & 66.8 & 19.7 & 7.2 & - & - & - & - & 187.4 & 34.1 \\
\hline Canola & - & 1 & - & - & - & 6.0 & - & 2.1 & 60.3 & 20.9 & 8.2 & 0.6 & 1.3 & 0.3 & 0.2 & 181.64 & 37.17 \\
\hline Canola & - & 1 & - & - & - & 4.0 & - & - & 60.5 & 20.3 & 9.4 & - & - & - & - & 180.4 & 39.1 \\
\hline Palm & - & 0 & 1 & 0.3 & 1.1 & 41.9 & 0.2 & 4.6 & 41.2 & 10.3 & 0.1 & 0.3 & - & - & - & 103.6 & 10.5 \\
\hline Palm & - & 0 & 1 & - & 1.0 & 40.1 & - & 4.1 & 43.0 & 11.0 & 0.2 & 0.3 & - & - & - & 108.52 & 11.44 \\
\hline Palm & - & 0 & 1 & - & - & 41.3 & - & 3.5 & 43.1 & 12.1 & - & - & - & - & - & 110.4 & 12.1 \\
\hline Palm & - & 0 & 1 & - & 0.6 & 47.2 & - & 3 & 40.8 & 8.2 & 0.2 & - & - & - & - & 98.4 & 8.6 \\
\hline Palm & - & 0 & 1 & - & - & 43.3 & - & - & 40.5 & 9.6 & 0.3 & - & - & - & - & 100.8 & 10.2 \\
\hline Palm & - & 0 & 1 & - & - & 40.3 & - & 3.1 & 43.4 & 13.2 & - & - & - & - & - & 113.2 & 13.2 \\
\hline Soybean & - & 1 & - & - & 0.1 & 11.0 & - & 4.3 & 23.1 & 53.3 & 6.8 & 0.3 & - & - & - & 166.32 & 66.81 \\
\hline Soybean & - & 1 & - & - & 0.1 & 10.8 & - & 4 & 23.4 & 53.9 & 7.8 & - & - & - & - & 170.2 & 69.5 \\
\hline Soybean & - & 1 & - & - & - & 14.1 & 0.7 & 5.2 & 25.3 & 48.7 & 6.1 & - & - & - & - & 161.6 & 60.9 \\
\hline Soybean & - & 1 & - & - & - & 10.5 & - & 4.1 & 24.1 & 53.6 & 7.7 & - & - & - & - & 170.8 & 69 \\
\hline Soybean & - & 1 & - & - & 0.1 & 11.0 & 0.1 & 4 & 23.4 & 53.2 & 7.8 & 0.3 & - & 0.1 & - & 169 & 68.8 \\
\hline Sunflower* & - & - & - & - & - & 4.5 & - & 4 & 82.0 & 8.0 & 0.2 & 0.3 & - & 1.0 & - & 180.4 & 8.4 \\
\hline Sunflower & - & - & - & - & 0.2 & 5.3 & - & 5.7 & 20.6 & 67.4 & 0.8 & - & - & - & - & 177.6 & 69 \\
\hline Sunflower & - & - & - & - & - & 6.0 & - & 4.7 & 24.0 & 63.7 & - & 0.3 & 0.2 & 0.8 & - & 175.84 & 63.74 \\
\hline Sunflower & - & - & - & 0.5 & 0.2 & 4.8 & 0.8 & 5.7 & 20.6 & 66.2 & 0.8 & 0.3 & - & - & - & 176.8 & 67.8 \\
\hline Canola/Palm & $3: 1$ & 0.75 & 0.25 & 0.1 & 0.3 & 13.9 & 0.2 & 2.7 & 58.5 & 17.7 & 5.7 & 0.6 & - & 0.2 & - & 164.35 & 29.18 \\
\hline Canola/Palm & $1: 3$ & 0.25 & 0.75 & 0.2 & 0.8 & 32.6 & 0.2 & 4.0 & 47.0 & 12.8 & 2.0 & 0.4 & - & 0.1 & - & 123.85 & 16.73 \\
\hline Canola/Palm & $1: 1$ & 0.5 & 0.5 & 0.2 & 0.6 & 23.3 & 0.2 & 3.4 & 52.8 & 15.3 & 3.9 & 0.5 & - & 0.2 & - & 144.1 & 22.95 \\
\hline Canola/Palm & $2: 3$ & 0.4 & 0.6 & - & 0.6 & 25.8 & - & 3.1 & 50.8 & 14.5 & 3.9 & 0.4 & 0.5 & - & - & 139.42 & 22.33 \\
\hline Canola/Palm & $3: 2$ & 0.6 & 0.4 & - & 0.4 & 18.7 & - & 2.6 & 54.6 & 16.3 & 5.8 & 0.5 & 0.8 & - & - & 154.86 & 27.78 \\
\hline Canola/Palm & $4: 1$ & 0.8 & 0.2 & - & 0.2 & 11.6 & - & 2.2 & 58.5 & 18.0 & 7.6 & 0.5 & 1.0 & - & - & 170.31 & 33.22 \\
\hline Canola/Soybean & $4: 1$ & 1 & - & - & 0.1 & 5.7 & - & 2.2 & 54.5 & 26.4 & 8.9 & 0.5 & 1.0 & - & - & 181.87 & 44.3 \\
\hline Canola/Soybean & $3: 2$ & 1 & - & - & 0.1 & 7.0 & - & 2.7 & 46.7 & 33.1 & 8.4 & 0.4 & 0.8 & - & - & 177.98 & 49.93 \\
\hline Canola/Soybean & $2: 3$ & 1 & - & - & 0.1 & 8.3 & - & 3.3 & 38.8 & 39.9 & 7.9 & 0.4 & 0.5 & - & - & 174.1 & 55.55 \\
\hline Canola/Soybean & $1: 4$ & 1 & - & - & 0.1 & 9.6 & - & 3.8 & 31.0 & 46.6 & 7.3 & 0.3 & 0.3 & - & - & 170.21 & 61.18 \\
\hline Canola/Soybean & $1: 3$ & 1 & - & - & - & 9.0 & 0.1 & 3.6 & 34.2 & 45.3 & 7.7 & 0.2 & - & 0.1 & - & 174.25 & 60.6 \\
\hline Canola/Soybean & $3: 1$ & 1 & - & - & - & 6.1 & 0.2 & 2.6 & 54.3 & 28.6 & 7.6 & 0.5 & - & 0.2 & - & 181.15 & 43.8 \\
\hline Canola/Soybean & $1: 1$ & 1 & - & - & - & 7.6 & 0.1 & 3.1 & 44.2 & 36.9 & 7.7 & 0.4 & - & 0.2 & - & 177.7 & 52.2 \\
\hline Canola/Sunflower* & $3: 1$ & 0.5 & - & - & - & 4.6 & 0.2 & 2.6 & 68.7 & 17.2 & 5.8 & 0.6 & - & 0.5 & - & 183.55 & 28.65 \\
\hline Canola/Sunflower* & $1: 3$ & 0.75 & - & - & - & 4.5 & 0.1 & 3.5 & 77.6 & 11.1 & 2.1 & 0.4 & - & 0.8 & - & 181.45 & 15.15 \\
\hline Canola/Sunflower* & $1: 1$ & 0.5 & - & - & - & 4.6 & 0.1 & 3.1 & 73.2 & 14.1 & 3.9 & 0.5 & - & 0.7 & - & 182.5 & 21.9 \\
\hline
\end{tabular}

*High oleic sunflower. 
(Table 10 continued.)

\begin{tabular}{|c|c|c|c|c|c|c|c|c|c|c|c|c|c|c|c|c|c|}
\hline FEEDSTOCK & $\begin{array}{l}\text { Blend } \\
\text { Ratio }\end{array}$ & V-T & $\pi$ & 12:0 & $14: 0$ & $16: 0$ & $16: 1$ & $18: 0$ & 18:1 & $18: 2$ & $18: 3$ & $20: 0$ & $20: 1$ & 22:0 & 22:1 & APE & BAPE \\
\hline Palm/Soybean & $9: 1$ & 0.1 & 0.9 & 0.3 & 1.0 & 38.8 & 0.2 & 4.6 & 39.5 & 14.6 & 0.9 & 0.3 & - & - & - & 110.32 & 16.35 \\
\hline Palm/Soybean & 1 & .2 & 0.8 & & 0.8 & 34.3 & - & 4.1 & 39.0 & 19.5 & 1.5 & .3 & - & - & - & 120.08 & 22.51 \\
\hline Palm/Soybean & $4: 1$ & 0.2 & 0.8 & 0.2 & 0.9 & 35.6 & 0.2 & 4.5 & 37.8 & 19.0 & 1.6 & 0.2 & - & - & - & 117.04 & 22.2 \\
\hline Palm/Soybean & $7: 3$ & 0.3 & 0.7 & 0.2 & 0.8 & 32.5 & 0.1 & 4.5 & 36.1 & 23.3 & 2.4 & 0.2 & - & - & - & 123.76 & 28.05 \\
\hline Palm/Soybean & $3: 2$ & 0.4 & 0.6 & & 0.6 & 28.4 & - & 4.2 & 35.1 & 27.9 & 2.8 & 0.3 & - & - & - & 131.64 & 33.59 \\
\hline Palm/Soybean & $3: 2$ & 0.4 & 0.6 & 0.2 & 0.7 & 29.3 & 0.1 & 4.4 & 34.4 & 27.6 & 3.1 & 0.2 & - & - & - & 130.48 & 33.9 \\
\hline Palm/Soybean & $1: 1$ & 0.5 & 0.5 & 0.2 & 0.6 & 26.2 & 0.1 & 4.4 & 32.7 & 32.0 & 3.9 & 0.2 & - & - & - & 137.2 & 39.75 \\
\hline Palm/Soybean & $2: 3$ & 0.6 & 0.4 & - & 0.4 & 22.6 & - & 4.2 & 31.1 & 36.4 & 4.1 & 0.3 & - & - & - & 143.2 & 44.66 \\
\hline Palm/Soybean & $2: 3$ & 0.6 & 0.4 & 0.1 & 0.4 & 23.1 & 0.1 & 4.3 & 30.9 & 36.3 & 4.7 & 0.1 & - & - & - & 143.92 & 45.6 \\
\hline Palm/Soybean & 3:7 & 0.7 & 0.3 & 0. & 0.3 & 19.9 & 0.1 & 4.3 & 29.2 & 40.6 & 5.4 & 0.1 & - & - & - & 150.64 & 51.45 \\
\hline Palm/S & 1 & $0 . \varepsilon$ & 0.2 & - & 0.3 & 16.8 & - & 4.3 & 27.1 & 44.8 & 5.5 & 0.3 & - & - & - & 154.76 & 55.74 \\
\hline Palm/Soybean & 1:4 & 0.8 & 0.2 & 0.1 & 0.2 & 16.8 & 0.0 & 4.2 & 27.5 & 44.9 & 6.2 & 0.1 & - & - & - & 157.36 & 57.3 \\
\hline Palm/Soybean & $1: 9$ & 0.9 & 0.1 & 0.0 & 0.1 & 13.6 & 0.0 & 4.2 & 25.8 & 49.3 & 6.9 & 0.0 & - & - & - & 164.08 & 63.15 \\
\hline Palm/Soybean & $1: 3$ & 0.75 & 0.25 & 0.1 & 0.3 & 18.4 & 0.1 & 4.2 & 28.4 & 42.8 & 5.8 & 0.1 & - & - & - & 154 & 54.38 \\
\hline Palm/Soybean & $3: 1$ & 0.25 & 0.75 & 0.2 & 0.8 & 34.1 & 0.2 & 4.5 & 36.9 & 21.1 & 2.0 & 0.2 & - & - & - & 120.4 & 25.13 \\
\hline Palm/Soybean & 1:1 & 0.5 & 0.5 & 0.2 & 0.6 & 26.2 & 0.1 & 4.4 & 32.7 & 32.0 & 3.9 & 0.2 & - & - & - & 137.2 & 39.75 \\
\hline Palm/Sunflower* & $3: 1$ & - & 0.75 & 0.2 & 0.8 & 32.6 & 0.2 & 4.5 & 51.4 & 9.7 & 0.1 & 0.3 & - & 0.3 & - & 122.8 & 9.975 \\
\hline Palm/Sunflower* & $1: 3$ & - & 0.25 & 0.1 & 0.3 & 13.9 & 0.1 & 4.2 & 71.8 & 8.6 & 0.2 & 0.3 & - & 0.8 & - & 161.2 & 8.925 \\
\hline Palm/Sunflower* & $1: 1$ & - & 0.5 & 0.2 & 0.6 & 23.2 & 0.1 & 4.3 & 61.6 & 9.2 & 0.2 & 0.3 & - & 0.5 & - & 142 & 9.45 \\
\hline Soybean/Sunflower* & $3: 1$ & 0.75 & - & - & - & 9.0 & - & 4.1 & 38.6 & 42.2 & 5.8 & 0.1 & - & 0.3 & - & 173.2 & 53.85 \\
\hline Soybean/Sunflower* & $1: 3$ & 0.25 & - & - & - & 6.0 & - & 4.0 & 67.5 & 19.4 & 2.1 & 0.2 & - & 0.8 & - & 178 & 23.55 \\
\hline Soybean/Sunflower* & $1: 1$ & 0.5 & - & - & - & 7.5 & - & 4.1 & 53.1 & 30.8 & 4.0 & 0.2 & - & 0.5 & - & 175.6 & 38.7 \\
\hline Palm/Canola/Soybean & $1: 1: 1$ & 0.666 & 0.333 & 0.1 & 0.4 & 18.8 & 0.1 & 3.6 & 42.8 & 27.8 & 5.1 & 0.3 & - & 0.1 & - & 151.47 & 37.92 \\
\hline Palm/Canola/Soybean & $3: 1: 1$ & 0.4 & 0.6 & - & 0.6 & 27.1 & - & 3.7 & 42.9 & 21.2 & 3.4 & 0.4 & 0.3 & - & - & 135.53 & 27.96 \\
\hline Palm/Canola/Soybean & $2: 2: 1$ & 0.6 & 0.4 & - & 0.4 & 20.0 & - & 3.2 & 46.8 & 23.0 & 5.2 & 0.4 & 0.5 & - & - & 150.98 & 33.41 \\
\hline Palm/Canola/Soybean & $2: 1: 2$ & 0.6 & 0.4 & - & 0.4 & 21.3 & - & 3.7 & 38.9 & 29.7 & 4.7 & 0.3 & 0.3 & - & - & 147.09 & 39.03 \\
\hline Palm/Canola/Soybean & $3 \cdot 1$ & 0.8 & 0.2 & - & 0.2 & 12.9 & - & 2.7 & 50.7 & 24.7 & 7.1 & 0.5 & 0.8 & - & - & 166.42 & 38.85 \\
\hline Palm/Canola/Soybean & $1: 2: 2$ & 0.8 & 0.2 & - & 0.2 & 12.9 & - & 2.7 & 50.7 & 24.7 & 7.1 & 0.5 & 0.8 & - & - & 166.42 & 38.85 \\
\hline Palm/Canola/Soybean & $1: 1: 3$ & 0.8 & 0.2 & - & 0.3 & 15.5 & - & 3.7 & 35.0 & 38.1 & 6.0 & 0.3 & 0.3 & - & - & 158.65 & 50.11 \\
\hline Canola/Palm/Sunflower* & 1:1:1 & 0.333 & 0.333 & 0.1 & 0.4 & 16.8 & 0.1 & 3.5 & 61.9 & 12.7 & 2.6 & 0.4 & - & 0.4 & - & 154.64 & 17.92 \\
\hline Soybean/Canola/Sunflower* & & 0.666 & - & - & - & 6.5 & 0.1 & 3.4 & 56.2 & 27.0 & 5.1 & 0.3 & - & 0.4 & - & 176.81 & 37.22 \\
\hline Soybean/Sunflower*/Palm & 1:1:1 & 0.333 & 0.3 & 0.1 & 0.4 & 18.8 & 0.1 & 4.2 & 48.6 & 23.7 & 2.6 & 0.2 & - & 0.3 & - & 150.08 & 29.01 \\
\hline $\begin{array}{l}\text { Soybean/Canola/ } \\
\text { Palm/Sunflower* }\end{array}$ & 1:1:1:1 & 0.5 & 0.25 & 0.1 & 0.3 & 15.4 & 0.1 & 3.7 & 52.9 & 23.0 & 3.9 & 0.3 & - & 0.3 & - & 159.85 & 30.83 \\
\hline
\end{tabular}

*High oleic sunflower.

Because regression analysis assumes that there exists a linear relationship between the dependent and the explanatory variables, it is necessary to investigate if there are any nonlinear relationships ${ }^{13}$. As can be seen in Figure A2, scatter plots of induction periods vs. BAPE and APE indices demonstrate a significant degree of linearity, with $\mathrm{R}^{2}$ values of 0.6085 and 0.4582 respectively ${ }^{14}$. As expected, FAMEs with higher BAPE and APE values have shorter induction periods.

13 If they exist, nonlinear to linear transformations might still enable regression analysis.

${ }^{14}$ Because we represent the $\gamma$-tocopherol and tocotrienol levels with dummy variables in the model, scatter plots for those variables are not included in this part. 

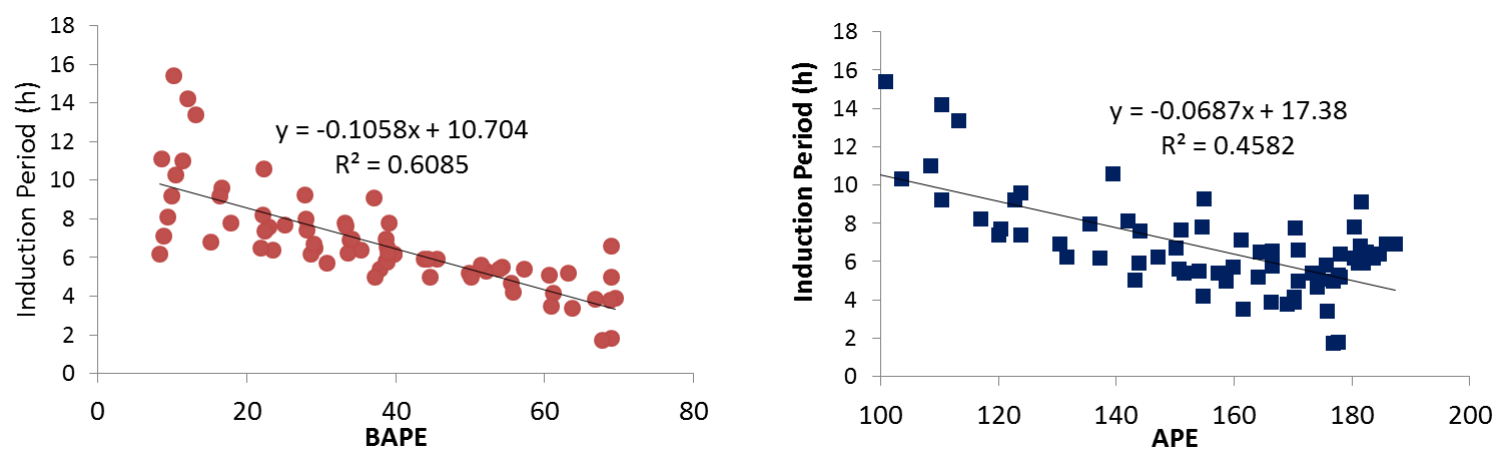

Figure A2 - Scatter plots of induction period vs. BAPE and APE indices of the FAMEs in Table 8.

Prior to running the multiple regression, we randomly selected 35 out of the 69 available data points as the training set, and used the remaining 34 points as the validation set later on. Multiple regression analysis on the training set resulted in $\mathrm{R}^{2}=0.84$, with BAPE, $\gamma$-tocopherol and tocotrienol as the explanatory variables. These variables are statistically significant at the $95 \%$ confidence level. Detailed parameters of the regression analysis are listed in Table A11:

Table A11 - Multiple regression analysis results for 0S.

\begin{tabular}{ccccccc}
\hline Term & Estimate & Std Error & t Ratio & Prob > |t & Lower 95\% & Upper 95\% \\
\hline Intercept & 7.41 & 0.702 & 10.54 & $<0.0001$ & 5.98 & 8.84 \\
BAPE & -0.092 & 0.014 & -6.40 & $<0.0001$ & -0.12 & -0.06 \\
V-T & 2.76 & 0.732 & 3.78 & 0.0007 & 1.27 & 4.25 \\
TT & 4.12 & 0.738 & 5.59 & $<0.0001$ & 2.62 & 5.63 \\
\hline
\end{tabular}

Thus, the regression equation for the induction period can be expressed as in Eqn A2:

$$
\text { Induction Period }=7.41-0.092 * B A P E+2.76 * \gamma_{-} T+4.12 * T T
$$

The model was validated on the validation set, and a reasonable fit was found with a root-meansquare error of 1.23. We then performed Monte Carlo simulations to demonstrate potential range of induction periods for each feedstock. The results are listed in Table A12. The numbers in bracket represent $5^{\text {th }}$ and $95^{\text {th }}$ percentile estimates. Modeled induction period ranges follow the general trend reported in the literature with palm oil having the highest OS among others. However, the upper bounds of measured values are considerably higher than the model prediction. We think that those values are outliers, and therefore are not captured by the regression equation. It is also possible that those outlier samples contained some sort of antioxidant additives in their composition.

Table A12 - Monte Carlo simulation results of induction periods (IPs) predicted by the regression model. The numbers in bracket represent the $5^{\text {th }}$ and $95^{\text {th }}$ percentile estimates.

\begin{tabular}{ccc}
\hline FAME & Model IP Estimate (h) & Measured IP in Literature (h) \\
\hline Canola & {$[6.0,6.8]$} & {$[6.4,9.1]$} \\
Soybean & {$[3.6,4.1]$} & {$[3.5,6.6]$} \\
Sunflower & {$[1.1,2.4]$} & {$[1.8,3.4]$} \\
Palm & {$[10.5,10.8]$} & {$[10.3,15.4]$} \\
\hline
\end{tabular}

ApPendix B: Chance-Constrained Optimization ApPlied to Biodiesel FeEdSTOCK BLENDING 
We begin by describing the theory behind CC optimization. Let $X_{i}$ be a normally distributed random variable with mean $\bar{X}_{i}$ and standard deviation $\sigma_{x_{i}} ; A_{i}$ a corresponding weighing coefficient; and $Y$ and $Z$ constants representing deterministic constraints. We define $\alpha$ and $\beta$ as confidence levels of meeting the specified constraint. Thus, the probability of meeting the constraint can be expressed as in Eqns B1\&B2:

$$
\begin{aligned}
& \operatorname{Pr}\left\{\sum_{i} A_{i} X_{i} \leq Y\right\} \geq \alpha \\
& \operatorname{Pr}\left\{\sum_{i} A_{i} X_{i} \geq Z\right\} \geq \beta
\end{aligned}
$$

Because we assume Gaussian distributions for the random variables in this model, we can transform Eqns B3 and B4 to obtain the standard normal distribution with mean $\mu=0$, and variance $\sigma^{2}=1$, and then use standard test coefficients corresponding to the chosen confidence levels. The test coefficient for Gaussian distribution is usually denoted by z-value. At the limit of meeting the constraint, $\sum_{i} A_{i} X_{i}$ approaches to $Y$ or $Z$. Thus:

$$
\begin{aligned}
& \frac{Y-\sum_{i} A_{i} \bar{X}_{i}}{\sigma_{M i x}} \geq z_{-} v a l_{\alpha} \rightarrow \sum_{i} A_{i} \bar{X}_{i}+z_{-} v a l_{\alpha} \sigma_{M i x} \leq Y \\
& \frac{-Z+\sum_{i} A_{i} \bar{X}}{\sigma_{M i x}} \geq z_{-} v a l_{\beta} \rightarrow \sum_{i} A_{i} \bar{X}_{i}-z_{-} v a_{\alpha} \sigma_{M i x} \geq Z
\end{aligned}
$$

where $\sigma_{\text {Mix }}$ refers to the pooled standard deviation of the mix.

CC optimization for the biodiesel blending problem can be formulated as in Eqns B5-B12. The objective is to minimize the total feedstock cost.

$$
\begin{aligned}
\text { Min: } & \sum_{i} P_{i} A_{i} \\
\text { Subject to: } & \sum_{i} A_{i}=D \\
& \sum_{i} A_{i} \leq S_{i} \\
& \frac{I V_{B}}{}+X(\alpha) \sigma_{I V_{B}} \leq I V_{\text {cons }} \\
& \overline{O S}_{B}-X(\alpha) \sigma_{O S_{B}} \geq O S_{\text {cons }} \\
& \overline{C N}_{B}-X(\alpha) \sigma_{C N_{B}} \geq C N_{\text {cons }} \\
& \overline{C F P P}_{B}+X(\alpha) \sigma_{C F P P_{B}} \leq C F P P_{\text {cons }}
\end{aligned}
$$




$$
\overline{G H G}_{B}+X(\alpha) \sigma_{G H G_{B}} \leq G H G_{\text {cons }}
$$

where;

$P_{i}:$ unit price of feedstock $i$

$A_{i}$ : volume proportion of feedstock $i$ in the blend

$D$ : total demand

$S_{i}$ : supply of feedstock $i$

$X(\alpha)$ : test coefficient for normal distribution, one-tailed

$\overline{I V}_{B}$ : mean iodine value of the blend

$I V_{\text {cons }}$ : iodine value constraint

$\sigma_{I V_{B}}$ : standard deviation of iodine value in the blend

$\overline{O S}_{B}$ : mean oxidation stability of the blend

$O S_{\text {cons }}$ : oxidation stability constraint

$\sigma_{O S_{B}}$ : standard deviation of oxidation stability in the blend

$\overline{C N}_{B}$ : mean cetane number of the blend

$C N_{\text {cons }}$ : cetane number constraint

$\sigma_{C N_{B}}$ : standard deviation of cetane number in the blend

$\overline{C F P P}_{B}$ : mean cold filter plugging point of the blend

$C F P P_{\text {cons }}$ : cold filter plugging point constraint

$\sigma_{C F P P_{B}}$ : standard deviation of cold filter plugging point in the blend

$\overline{G H G}_{B}$ : mean GHG of the blend

$G H G_{\text {cons }}$ : GHG constraint

$\sigma_{G H G_{B}}$ : standard deviation of GHG in the blend

The amounts of each feedstock to be blended, namely $A_{i}$, constitute the decision variables of the optimization problem. Choosing a set of $A_{i}$ values determines the amount of each FA, $a_{j}$, in the blend. Because FAs are the building blocks that define all the physical parameters, we can derive IV, CN, OS and CFPP based on the FA profile of the blend. The following equations outline how this derivation is performed.

Mean physical parameter values are derived as in Eqns B13-B19:

$$
\begin{aligned}
& \bar{a}_{j}=\sum_{i, j} A_{i} \bar{C}_{j i} \\
& \overline{I V}_{B}=\sum_{j} \bar{a}_{j} I V_{j} \\
& \overline{B A P E}_{B}=100 *\left(\sum_{j} \bar{a}_{j}: j \text { has two double bonds }\right)+200 \\
& \qquad\left(\sum_{j} \bar{a}_{j}: j \text { has three double bonds }\right) \\
& \overline{O S}_{B}=\operatorname{Interc}_{O S}+C_{B A P E} * \overline{B A P E}_{B}+C_{\gamma T} * \gamma T+C_{T T} * T T \\
& \overline{C N}_{B}=\sum_{j} \bar{a}_{j} C N_{j}
\end{aligned}
$$




$$
\begin{aligned}
& \overline{C F P P}_{B}=\text { Interc }_{C F P P}+* C_{C F P P}\left(\sum_{j} \bar{a}_{j}: j \text { is saturated }\right) \\
& \overline{G H G}_{B}=\sum_{i} \overline{G H G}_{i} * A_{i}
\end{aligned}
$$

where;

$\bar{a}_{j}:$ mean composition of FA $j$ in the blend

$\bar{C}_{j i}$ : mean composition of FA $j$ in feedstock $i$

$I V_{j}$ : iodine value of $\mathrm{FA} j$

$\overline{B A P E}_{B}$ : mean BAPE of the blend

Inter $_{O S}$ : intercept in the oxidation stability regression equation

$C_{B A P E}$ : coefficient of BAPE in the oxidation stability regression equation

$C_{\gamma T}$ : coefficient of $\gamma$-tocopherol in the oxidation stability regression equation

$\gamma T$ : amount of $\gamma$-tocopherol in the blend

$C_{T T}$ : coefficient of tocotrienol in the oxidation stability regression equation

$T T$ : amount of tocotrienol in the blend

$C N_{j}$ : cetane number of $\mathrm{FA} j$

$C F P P_{j}$ : cold filter plugging point of $\mathrm{FA} j$

Inter $_{C F P P}$ : intercept in the cold filter plugging point regression equation

$C_{C F P P}$ : coefficient of total saturation in the cold filter plugging point regression equation

$\overline{G H G}_{i}$ : mean GHG of feedstock $i$

Standard deviations are derived as in Eqns B20-B25:

$$
\begin{aligned}
& \sigma_{j}=\sqrt{\sum_{i, j} A_{i}{ }^{2} \sigma_{j i}^{2}} \\
& \sigma_{I V_{B}}=\sqrt{\sum_{i, j} I V_{j}^{2} \sigma_{j i}^{2}} \\
& \sigma_{C N_{B}}=\sqrt{\sum_{i, j} C N_{J}^{2} \sigma_{j i}^{2}}{ }^{2}{ }_{\sigma_{O S_{B}}}=\sqrt{C_{B A P E}{ }^{2}\left(\sum_{i, j=18: 2} \sigma_{j i}^{2}+2^{2} \sum_{i, j=18: 3} \sigma_{j i}^{2}\right)} \\
& \sigma_{C F P P_{B}}=\sqrt{C_{C F P P}{ }^{2} \sum_{i, j=12: 0,14: 0,16: 0,18: 0} \sigma_{j i}^{2}} \\
& \sigma_{G H G_{B}}=\sqrt{\sum_{i} A_{i}{ }^{2} \sigma_{G H G_{i}}{ }^{2}}
\end{aligned}
$$

where;

$\sigma_{j}$ : standard deviation of composition of FA $j$ in the blend

$\sigma_{j i}$ : standard deviation of composition of FA $j$ in feedstock $i$

$\sigma_{G H G_{i}}$ : standard deviation of GHG emissions of feedstock $i$

Finally, it must be noted that there is another layer of $U \& V$ factor for the predicted properties OS and CFPP. This U\&V stems from the standard errors in their prediction coefficients, and should be 
propagated similar to the compositional U\&V. Yet, because the prediction coefficients are multiplied by the relevant FA compositions, estimating the variance of the product becomes nontrivial. The exact variance of a product of two random variables was derived by Goodman in 1960 [27]. In Eqn. B26 we refer to an approximation to estimate the variance of two random variables that are independent from each other:

$$
\operatorname{var}(X Y)=\bar{X}^{2} * \operatorname{var}(Y)+\bar{Y}^{2} * \operatorname{var}(X)+\operatorname{var}(X) * \operatorname{var}(Y)
$$

In Eqns B27\&B28, we outline the set of statements that would be used if the standard error in the BAPE coefficient for OS prediction, and the standard error in the total saturation coefficient for CFPP were taken into account. ${ }^{15}$ However, note that these complex estimates have not been used to obtain the results reported in the subsequent chapters.

$$
\begin{aligned}
& \sigma_{O S_{B}}=\left[C_{B A P E}{ }^{2}\left(\sum_{i, j=18: 2} \sigma_{j i}^{2}+2^{2} \sum_{i, j=18: 3} \sigma_{j i}^{2}\right)+\overline{B A P E}_{B}{ }^{2} \sigma_{C_{B A P E}}^{2}\right. \\
& \left.+\left(\sum_{i, j=18: 2} \sigma_{j i}^{2}+2^{2} \sum_{i, j=18: 3} \sigma_{j i}^{2}\right) \sigma_{C_{B A P E}}^{2}\right]^{1 / 2} \\
& \sigma_{C F P P_{B}}=\left[C_{C F P P}{ }^{2} \sum_{i, j=12: 0,14: 0,16: 0,18: 0} \sigma_{j i}^{2}+\overline{C F P P}_{B}{ }^{2} \sigma_{C_{C F P P}}{ }^{2}\right. \\
& \left.+\sum_{i, j=12: 0,14: 0,16: 0,18: 0} \sigma_{j i}^{2} \sigma_{C_{C F P P}} 2\right]^{1 / 2}
\end{aligned}
$$

where;

$$
\begin{aligned}
& \sigma_{C_{B A P E}}: \text { standard deviation of BAPE coefficient in the OS regression equation } \\
& \sigma_{C_{C F P P}}: \text { standard deviation of CFPP coefficient in the CFPP regression equation }
\end{aligned}
$$

\section{SENSITIVITY ANALYSIS ON CONSTRAINT LEVELS}

In order to observe how the historical blend portfolios and costs would differ with respect to changing constraint levels in CFPP, OS and GHG, we ran the CC optimization model on the monthly data between January 2003 and June 2011. Because CN and IV rarely become binding, we excluded them from the analyses in this section.

\section{SENSITIVITY ON THE CFPP CONSTRAINT}

Figure B1 shows how the historical optimal portfolios change when the maximum CFPP limit is (a) $2^{\circ} \mathrm{C}$, (b) $-1^{\circ} \mathrm{C}$ and (c) $0^{\circ} \mathrm{C}$. We see a reduction in the overall use of canola and an increase in palm and sunflower as the constraint is relaxed.

\footnotetext{
${ }^{15}$ In fact, OS prediction has two more coefficients, g-tocopherol and tocotrienol coefficients, that possess standard errors. For simplicity of illustration, we did not include them here.
} 


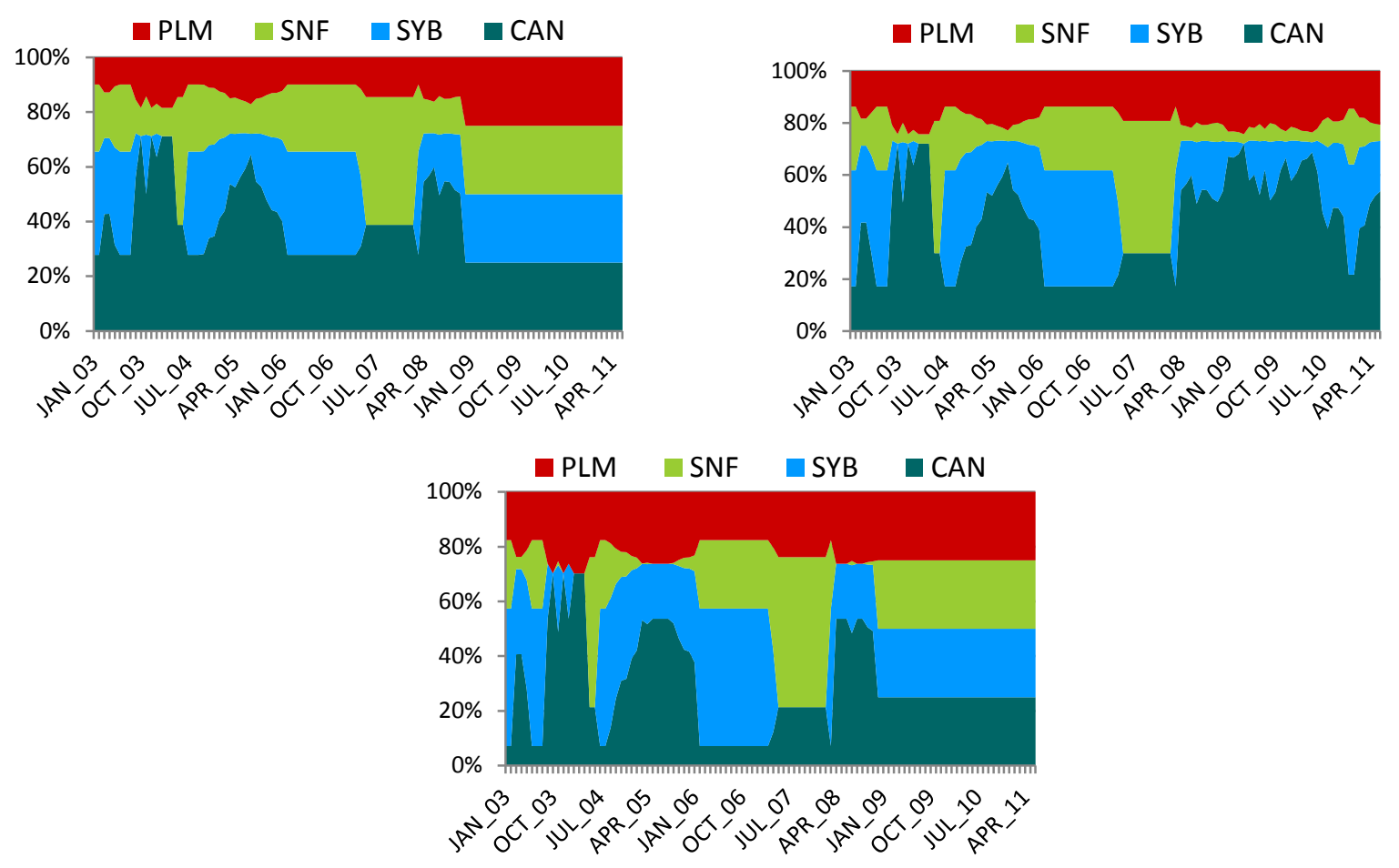

Figure B1 - Historical optimal blend portfolios when the CFPP constraint is (a) $-2{ }^{\circ} \mathrm{C}$, (b) $-1^{\circ} \mathrm{C}$ and $(\mathrm{c}) 0^{\circ} \mathrm{C}$.

Figure B2 shows the resulting feedstock cost of biodiesel over time. The differences between the curves reflect the marginal cost of tightening the constraint from $0^{\circ} \mathrm{C}$ to $-1^{\circ} \mathrm{C}$, and from $-1^{\circ} \mathrm{C}$ to $-2^{\circ} \mathrm{C}$. Depending on the relative prices of feedstocks, some months demonstrate a relatively high cost difference, whereas in other months, feedstock cost of biodiesel almost converges to a single point.

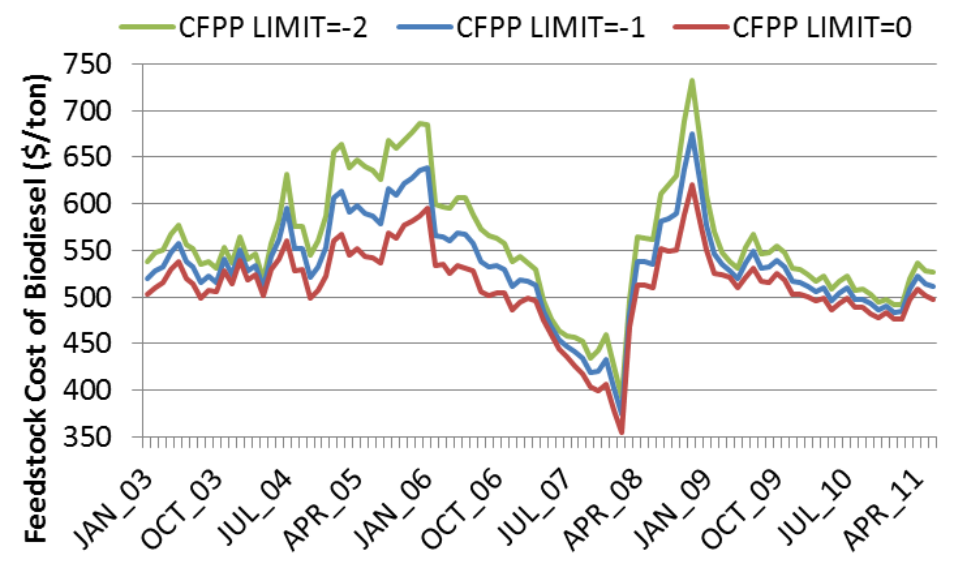

Figure B2 - Feedstock cost of biodiesel subject to different CFPP limits.

\section{SENSITIVITY ON THE OS CONSTRAINT}

Figure B3 shows how the historical optimal portfolios change when the minimum OS limit is (a) 6 hours, (b) 4.5 hours, and (c) 3 hours. A reduction in the overall use of canola and an increase in soybean are observed as the constraint is relaxed from 6 hours to 3 hours. The particular increase in the use of soybean explains why the US industry standard for OS is only 3 hours. Soybean is the 
most common domestic biodiesel feedstock in the US and can be a very attractive option for the producer when the OS limit is low.

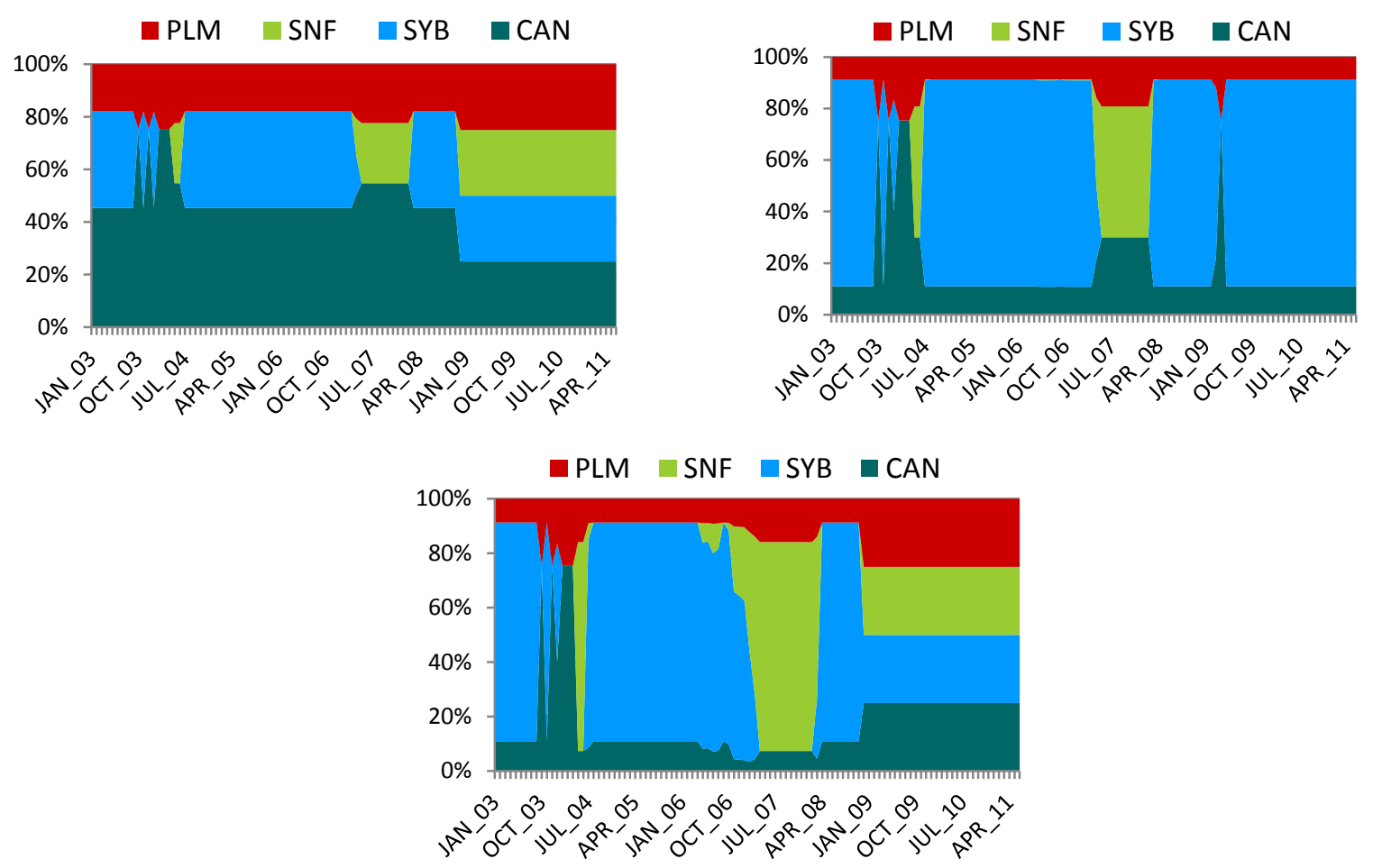

Figure B3 - Historical optimal blend portfolios when the OS constraint is (a) 6 hours, (b) 4.5 hours, and (c) 3 hours.

Figure B4 shows the resulting feedstock cost of biodiesel. As expected, a relaxation of the constraint results in lower costs overall. Although correlated fluctuations can be observed in general, the period between August 2007 and January 2008 demonstrates an interesting trend: there is a cost peak for the 6-hour constraint in contrast to the apparent cost decrease for the 4.5-hour and 3-hour constraints. This happens due to the fact that canola is needed in high proportions to achieve at least 6 hours of induction period. The deflated price of canola increased compared to the other vegetable oils during August 2007-January 2008. A closer look at December 2007 results in Figure B4 reveals the significance of constraint levels on the cost competitiveness of biodiesel: Feedstock cost is about $\$ 525 /$ ton when the OS limit is 6 hours and $\$ 348 /$ ton when the OS limit is 3 hours-- a cost increase by more than $65 \%$. 


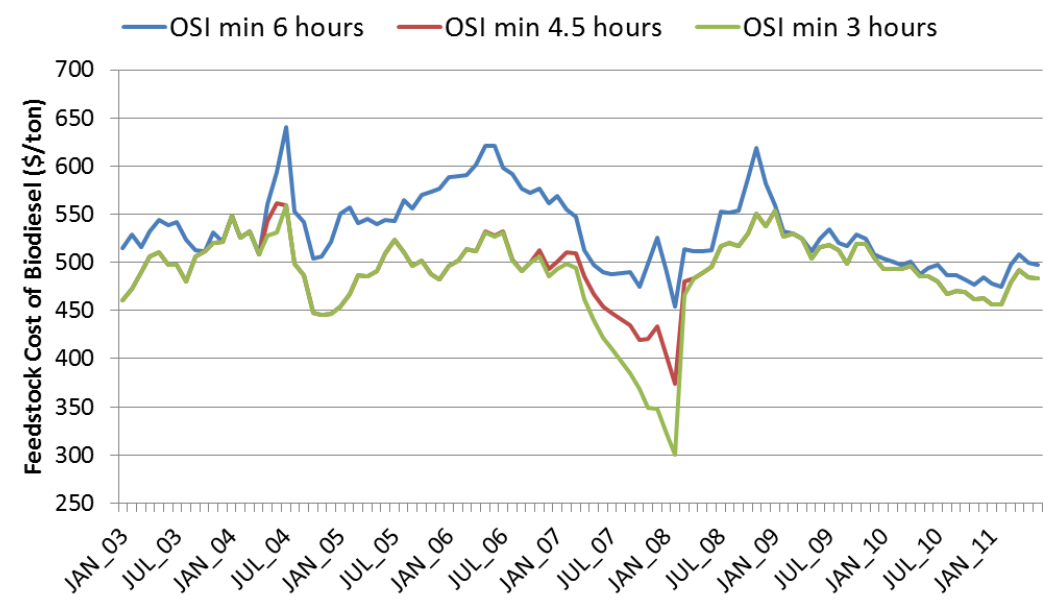

Figure B4 - Feedstock cost of biodiesel subject to different OS limits.

\section{APPENDICIES BIBLIOGRAPHY}

[1] G. Knothe, J. Van Gerpen, J. Krahl, and C. Press, The Biodiesel Handbook, 2nd ed.: AOCS press Champaign, IL, 2010.

[2] R. Snee, "Developing blending models for gasoline and other mixtures," Technometrics, vol. 23, pp. 119-130, 1981.

[3] W. Healy Jr, C. Maassen, and R. Peterson, "A NEW APPROACH TO BLENDING OCTANES f," 1959, p. 132.

[4] P. Ghosh and S. Jaffe, "Detailed composition-based model for predicting the cetane number of diesel fuels," Ind. Eng. Chem. Res, vol. 45, pp. 346-351, 2006.

[5] J. Kinast, "Production of biodiesels from multiple feedstocks and properties of biodiesels and biodiesel/diesel blends," Golden, Colorado: National Renewable Energy Laboratory, Gas Technology Institute, 2003.

[6] G. Knothe, A. C. Matheaus, and T. W. Ryan, "Cetane numbers of branched and straight-chain fatty esters determined in an ignition quality tester," Fuel, vol. 82, pp. 971-975, 2003.

[7] P. Ghosh and S. B. Jaffe, "Detailed composition-based model for predicting the cetane number of diesel fuels," Industrial \& Engineering Chemistry Research, vol. 45, pp. 346-351, 2006.

[8] M. Murphy, J. Taylor, and R. McCormick, "Compendium of experimental cetane number data," Contract DE-AC36-99-G010337. Golden CO: National Renewable Energy Laboratory, 2004.

[9] B. Freedman and M. Bagby, "Predicting cetane numbers of n-alcohols and methyl esters from their physical properties," Journal of the American Oil Chemists' Society, vol. 67, pp. 565-571, 1990.

[10] B. R. Moser, "Influence of Blending Canola, Palm, Soybean, and Sunflower Oil Methyl Esters on Fuel Properties of Biodiesel†," Energy \& Fuels, vol. 22, pp. 4301-4306, 2008.

[11] H. Imahara, E. Minami, and S. Saka, "Thermodynamic study on cloud point of biodiesel with its fatty acid composition," Fuel, vol. 85, pp. 1666-1670, 2006.

[12] E. N. Frankel, Lipid oxidation: Oily Press Dundee, Scotland, 1998.

[13] A. Kamal-Eldin, "Effect of fatty acids and tocopherols on the oxidative stability of vegetable oils," European Journal of Lipid Science and Technology, vol. 108, pp. 1051-1061, 2006. 
[14] G. Knothe, "Structure indices in FA chemistry. How relevant is the iodine value?," Journal of the American Oil Chemists' Society, vol. 79, pp. 847-854, 2002.

[15] A. Fröhlich and S. Schober, "The influence of tocopherols on the oxidation stability of methyl esters," Journal of the American Oil Chemists' Society, vol. 84, pp. 579-585, 2007.

[16] M. Mittelbach and S. Schober, "The influence of antioxidants on the oxidation stability of biodiesel," Journal of the American Oil Chemists' Society, vol. 80, pp. 817-823, 2003.

[17] S. Jain and M. Sharma, "Stability of biodiesel and its blends: a review," Renewable and sustainable energy reviews, vol. 14, pp. 667-678, 2010.

[18] D. Dolde, C. Vlahakis, and J. Hazebroek, "Tocopherols in breeding lines and effects of planting location, fatty acid composition, and temperature during development," Journal of the American Oil Chemists' Society, vol. 76, pp. 349-355, 1999.

[19] W. W. Christie. (2012, January). The AOCS Lipid Library, Tocopherols and Tocotrienols. Available: http://lipidlibrary.aocs.org/lipids/tocol/index.htm

[20] G. Knothe and R. O. Dunn, "Dependence of oil stability index of fatty compounds on their structure and concentration and presence of metals," Journal of the American Oil Chemists' Society, vol. 80, pp. 1021-1026, 2003.

[21] S. Schober and M. Mittelbach, "Antioxidants In: Stability of Biodiesel-Used as a Fuel for Diesel Engines and Heating Systems. Presentation of the BIOSTAB Project Results: Proceedings, Graz July 3rd (2003), editor BLT Wieselburg, Austria," ISBN 3-902451-00-9.

[22] J. Y. Park, D. K. Kim, J. P. Lee, S. C. Park, Y. J. Kim, and J. S. Lee, "Blending effects of biodiesels on oxidation stability and low temperature flow properties," Bioresource Technology, vol. 99, pp. 1196-1203, 2008.

[23] H. Tang, R. C. De Guzman, S. O. Salley, and S. K. Y. Ng, "The oxidative stability of biodiesel: Effects of FAME composition and antioxidant," Lipid Technology, vol. 20, pp. 249-252, 2008.

[24] B. R. Moser, "Comparative oxidative stability of fatty acid alkyl esters by accelerated methods," Journal of the American Oil Chemists' Society, vol. 86, pp. 699-706, 2009.

[25] R. Sarin, M. Sharma, S. Sinharay, and R. Malhotra, "Jatropha-Palm biodiesel blends: An optimum mix for Asia," Fuel, vol. 86, pp. 1365-1371, 2007.

[26] J. Polavka, J. Paligová, J. Cvengroš, and P. Simon, "Oxidation stability of methyl esters studied by differential thermal analysis and Rancimat," Journal of the American Oil Chemists' Society, vol. 82, pp. 519-524, 2005.

[27] L. A. Goodman, "On the exact variance of products," Journal of the American Statistical Association, pp. 708-713, 1960. 